\title{
Mucosal-associated invariant T cell-rich congenic mouse strain allows functional evaluation
}

\author{
Yue Cui, ${ }^{1}$ Katarzyna Franciszkiewicz, ${ }^{1}$ Yvonne K. Mburu, ${ }^{1}$ Stanislas Mondot, ${ }^{1}$ Lionel Le Bourhis, ${ }^{1}$ Virginie Premel, ${ }^{1}$ \\ Emmanuel Martin, ${ }^{1}$ Alexandra Kachaner, ${ }^{1}$ Livine Duban, ${ }^{1}$ Molly A. Ingersoll, ${ }^{2}$ Sylvie Rabot, ${ }^{3,4}$ Jean Jaubert, ${ }^{5}$ \\ Jean-Pierre De Villartay, ${ }^{6}$ Claire Soudais, ${ }^{1}$ and Olivier Lantz ${ }^{1,7,8,9}$
}

IInstitut Curie, INSERM U932, Paris, France. ${ }^{2}$ Dendritic Dell Immunobiology Unit and INSERM U818, Institut Pasteur, Paris, France. ${ }^{3}$ NRRA, UMR1319, Micalis, Jouy-en-Josas, France. ${ }^{4}$ AgroParisTech, Micalis,

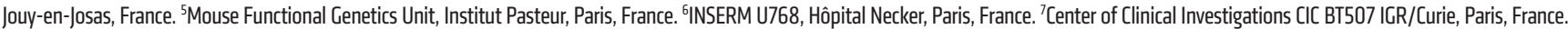
${ }^{8}$ Equipe Labellisée de la Ligue de Lutte Contre le Cancer, Institut Curie, Paris, France. ${ }^{9}$ Département de Biopathologie, Institut Curie, Paris, France.

\begin{abstract}
Mucosal-associated invariant T cells (MAITs) have potent antimicrobial activity and are abundant in humans (5\%-10\% in blood). Despite strong evolutionary conservation of the invariant TCR- $\alpha$ chain and restricting molecule MR1, this population is rare in laboratory mouse strains ( $\approx 0.1 \%$ in lymphoid organs), and lack of an appropriate mouse model has hampered the study of MAIT biology. Herein, we show that MAITs are 20 times more frequent in clean wild-derived inbred CAST/EiJ mice than in C57BL/6J mice. Increased MAIT frequency was linked to one CAST genetic trait that mapped to the TCR- $\alpha$ locus and led to higher usage of the distal V $\alpha$ segments, including V $\alpha 19$. We generated a MAIT ${ }^{\text {hi }}$ congenic strain that was then crossed to a transgenic Rorcgt-CFP reporter strain. Using this tool, we characterized polyclonal mouse MAITs as memory (CD44 ${ }^{+}$) CD4-CD8 ${ }^{\text {lo/neg }}$ T cells with tissue-homing properties (CCR6+CCR7-). Similar to human MAITs, mouse MAITs expressed the cytokine receptors IL-7R, IL-18R $\alpha$, and IL-12R $\beta$ and the transcription factors promyelocytic leukemia zinc finger (PLZF) and RAR-related orphan receptor $\gamma$ (ROR $\gamma \mathrm{t}$ ). Mouse MAITs produced Th1/2/17 cytokines upon TCR stimulation and recognized a bacterial compound in an MR1-dependent manner. During experimental urinary tract infection, MAITs migrated to the bladder and decreased bacterial load. Our study demonstrates that the MAIT ${ }^{\text {hi }}$ congenic strain allows phenotypic and functional characterization of naturally occurring mouse MAITs in health and disease.
\end{abstract}

\section{Introduction}

Mucosal-associated invariant T cells (MAITs) express an invariant TCR- $\alpha$ (iTCR- $\alpha$ ) chain (iV $\alpha 7.2-J \alpha 33$ in human and iV $\alpha 19-J \alpha 33$ in mouse) restricted by the major histocompatibility complex (MHC) class I-related protein 1 (MR1) (1-4). MAITs recognize bacteria-infected cells $(5,6)$ and display antimicrobial activity in several experimental infection models (6-8). There is a strict correlation between the capacities of a bacterial strain to activate MAITs and to synthesize riboflavin (vitamin B2) (rib) $(6,9)$. Indeed, MAITs specifically recognize derivatives of the rib biosynthetic pathway, which is absent from mammals, but present in most bacteria and in yeasts $(9,10)$.

MAITs are decreased in the blood of patients suffering from subacute $(5,6)$ or acute infections (11) and are detected at the site of infection. The frequency of MAITs is also modified in nonbacterial diseases: increased in recently diagnosed multiple sclerosis patients $(12,13)$, but decreased in obesity, type-2 diabetes (14), inflammatory bowel disease (15), and HIV (16-19).

MAITs are CD4 ${ }^{-} \mathrm{CD}^{-}$(DN) (and also CD8 $\alpha \alpha$ in humans) or CD $8 \alpha \beta^{\text {int }}$. They are abundant in the blood ( $\left.1 \%-10 \%\right)$, gut $(3 \%-5 \%)$, and liver $(20 \%-50 \%)$ of humans, but are extremely rare in labo-

Authorship note: Yue Cui and Katarzyna Franciszkiewicz contributed equally to this work. Conflict of interest: The authors have declared that no conflict of interest exists. Submitted: April 17, 2015; Accepted: September 3, 2015.

Reference information: / Clin Invest. 2015;125(11):4171-4185. doi:10.1172/JCI82424. ratory mouse strains (20-22). The disparity in frequency between species contrasts with the high conservation of both the TCR- $\alpha$ and MR1 molecules, which indicates a strong evolutionary selection pressure and thereby important functions (23).

The phenotype and functional properties of MAITs are much better known in humans than in mice. Human MAITs from adult peripheral blood display an effector memory pheno-

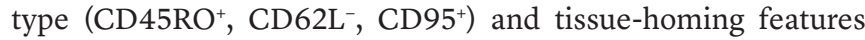
$\left(\mathrm{CCR}^{+}, \mathrm{CCR} 5+, \mathrm{CCR}^{+}, \mathrm{CXCR}^{+}, \mathrm{CCR}^{+}, \mathrm{CCR}^{-}\right)(21,24)$. They secrete high amounts of IFN- $\gamma$, TNF- $\alpha$, and granulocyte-macrophage CSF (GM-CSF) and have the potential to secrete IL-17 and IL-22 (21, 24-26), but not Th2 cytokines $(21,27)$. MAITs are cytotoxic for epithelial cells infected by invasive bacteria $(28,29)$. In addition to TCR triggering, MAITs can be activated by innate cytokines such as IL-12 and IL-18 (25, 30). Consistent with their innate-like features and IL-17 secretion capacity, MAITs express the transcription factors ZBTB16 (promyelocytic leukemia zinc finger $[\mathrm{PLZF}])$ and RAR-related orphan receptor $\gamma(\mathrm{ROR} \gamma \mathrm{t})(21$, $24,31,32)$.

In the cord blood, human MAITs display a naive phenotype, and their TCR- $\beta$ repertoire is diverse $(21,22)$. After birth, MAITs expand to reach high clonal size $(20,33)$. This contrasts with the low cell-division rate of MAITs in human adult blood, shown by low Ki-67 expression $(21,34)$. Taken together, these data indicate that MAITs either proliferated during childhood or undergo division in the tissues and recirculate to the blood once resting. 
Table 1. Fine mapping of the MAIT ${ }^{\text {hi }}$ locus in informative recombinant mice generated during backcrossing MAIT ${ }^{\text {CAST }}$ phenotype to B6

\begin{tabular}{|c|c|c|c|c|c|c|c|c|c|}
\hline \multirow[b]{2}{*}{$V \alpha 19-J \alpha 33^{A}$} & \multicolumn{9}{|c|}{ Mbp (on chromosome 14) } \\
\hline & 53.70 & 54.25 & 54.40 & 54.70 & 54.83 & 54.86 & 55.00 & 56.00 & 57.00 \\
\hline 0.7 & B6 & B6 & B6 & B6 & B6 & B6 & B6 & Het & Het \\
\hline 0.44 & B6 & B6 & B6 & B6 & B6 & B6 & Het & Het & Het \\
\hline 0.95 & Het & Het & B6 & B6 & B6 & B6 & B6 & B6 & $\mathrm{B} 6$ \\
\hline 6.99 & Het & Het & Het & Het & Het & B6 & B6 & B6 & B6 \\
\hline
\end{tabular}

${ }^{A} V_{\alpha 19-J} 333$ mRNA levels measured by RT-qPCR in blood or MLNs. Fold change relative to B6 MLNs, after normalization to C $\alpha$. Bold indicates the most informative recombination point.

In contrast to human, mouse MAITs are extremely rare in common laboratory mouse strains. So far, the study of MAIT physiology has mostly relied on mice that are Tg for the MAIT TCR chains. Several iV $\alpha 19$ TCR- $\alpha$ Tg strains have been produced $(32,35,36)$. In $\mathrm{iV} \alpha 19 \mathrm{Tg} \mathrm{Ca}^{-/-}$(to prevent the expression of endogenous TCR- $\alpha$ chains) mice, on an MR1-sufficient background, the DN and CD8 ${ }^{\text {lo }} \mathrm{T}$ cells display an increased usage of the V $\beta 6$ and V $\beta 8$ TCR- $\beta$ segments $(32,36,37)$. Most of these $\mathrm{V} \beta 6^{+}$or $\mathrm{V} \beta 8^{+} \mathrm{T}$ cells are activated by bacteria $(6,38)$. These TCR- $\alpha$ Tg models allow the study of MAIT specificity and antibacterial activity in vitro and in vivo $(6,39,40)$, even if, in contrast to humans, most MAITs display a naive CD44 ${ }^{\text {lo }}$ phenotype (32). This is probably related to the forced premature expression of the TCR- $\alpha$ chain transgene, which also greatly modifies the functionality of the Tg T cells (41). This casts doubt on the relevance of these TCR Tg laboratory mouse models for studying the physiological functions of MAITs. Likewise, in non-TCR Tg mouse models, antibody-mediated (8) or genetic (6) depletion of conventional T cells was necessary to evidence the role of MAITs in experimental infections. Thus, the phenotype as well as the function of naturally occurring mouse MAITs in health and disease remains to be addressed.

Two possibilities arise to explain the low frequency of MAITs in laboratory mice: (a) mice from animal facilities lack specific bacterial strains or communities in their microbiota that are necessary to sufficiently expand MAITs or (b) during the genetic bottleneck that occurred upon their establishment, laboratory mice lost an allele necessary for MAIT peripheral activation, expansion, or survival. We first studied the environmental hypothesis and then found that laboratory mouse strains have lost one genetic element implicated in MAIT development. A "MAITh" congenic strain was generated and further crossed to a Rorcgt-GFP ${ }^{T G}$ reporter strain. Most of the $\mathrm{GFP}^{+}$memory DNCD8 ${ }^{\text {lo }} \mathrm{T}$ cells were identified as MAIT, according to the expression of the iV $\alpha 19$ TCR- $\alpha$ chain and MR1 dependence. Using this tool, we analyzed the phenotype, peripheral expansion, and functions of naturally occurring mouse MAITs in health and in experimental urinary tract infection (UTI).

\section{Results}

Reconstitution of germ-free mice with human microbiota is insufficient to increase the number of MAITs above that found in specific pathogen-free-raised mice. We previously showed that colonization of germ-free (GF) mice with 1 microbial species is sufficient to increase the number of MAITs to the levels found in mice of specific pathogen-free (SPF) facilities (6). However, the number of MAITs was still much lower than that found in humans. This could be due to a lack of a specific bacterial strain or combination thereof that is only found in humans.

To test this hypothesis, we reconstituted breeding GF mice with a human microbiota and examined the frequency of MAITs in the pups 4 to 8 weeks after weaning. To increase the reliability of our experiment, we used $\mathrm{Tap}^{-/-} \mathrm{Ii}^{-/-}$mice, which harbor 10-fold more MAITs than C57BL/6J (B6) mice (32). We verified that the human microbiota had implanted (Supplemental Figure 1; supplemental material available online with this article; doi:10.1172/ JCI82424DS1) and measured MAIT frequency in the colon lamina propria (LP) by quantitative reverse-transcription PCR (RTqPCR) of the specific V $\alpha 19-J \alpha 33$ (iV $\alpha 19)$ TCR- $\alpha$ chain transcripts. We found that the frequency of MAITs in mice reconstituted with human microbiota was similar to that found in mice from our SPF facility (Figure 1A). This result suggests that the small number of MAITs found in mice from SPF animal facilities is probably not due to the absence of specific microbes or combinations thereof.

The CAST/EiJ mouse strain harbors 20 times more MAITs than $B 6$ mice. To test the genetic hypothesis that would explain the low number of MAITs in laboratory mice, we next measured MAIT frequency in SPF inbred mouse strains harboring a wider genetic diversity than conventional laboratory mice. Among 7 wild mouse strains tested (data not shown), we found 2 with increased frequency of MAITs: Mus musculus castaneus (CAST/EiJ abbreviated CAST) and Mus musculus musculus PWK (Figure 1B). We focused on the CAST strain that harbored the highest frequency of MAITs $(15.4 \pm 7.3 \mathrm{AU}$, mean $\pm \mathrm{SD})$. To assess the genetic basis of this phenotype, we crossed CAST (MAIT ${ }^{\mathrm{hi}}$ ) to B6 $\left(\mathrm{MAIT}^{\mathrm{lo}}\right.$ ) to generate F1 mice. The frequency of MAITs in F1s was intermediate (Figure 1B). To determine the number of loci involved, we crossed the F1s to B6s to generate N2s (Figure 1B). The N2s segregated into 2 groups of roughly equal size with either low or intermediate frequency of MAITs, suggesting that only 1 locus is responsible for the MAIT ${ }^{\text {hi }}$ phenotype. This result allowed a straightforward linkage analysis on 66 N2s using 4,700 informative SNPs distinguishing B6 and CAST. We identified a single locus in a $20-\mathrm{Mb}$ region on chromosome 14 (Figure 1C) linked with the MAIT ${ }^{\text {hi }}$ phenotype. To confirm this analysis, we also generated F2s and correlated the iV $\alpha 19$ levels in mesenteric lymph nodes (MLNs) with the genotypes (B6/B6, B6/CAST, CAST/CAST) of the previously mapped regions (Figure 
A
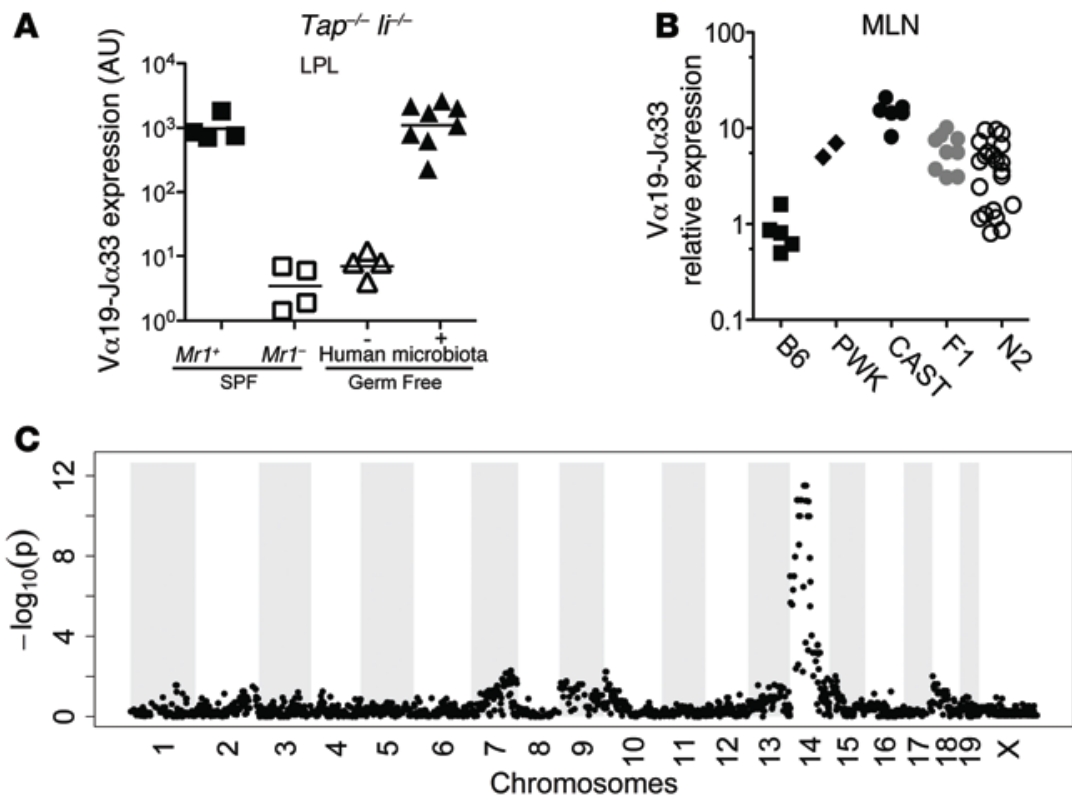

E
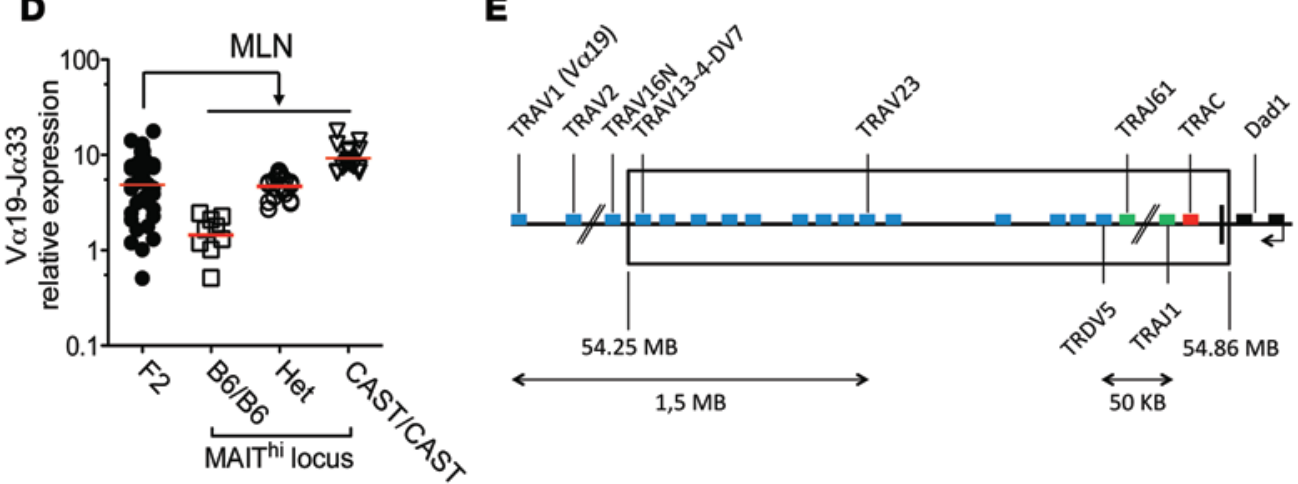

Figure 1. MAIT abundance in mouse is determined by genetic background rather than a limited microbiota. (A) Normalized Va19-J $\alpha 33$ mRNA levels in the LP of the progeny of GF $\mathrm{Mr}^{+} \mathrm{Tap}^{-1-}$ $1 i^{-/-}$breeding pairs reconstituted or not with human microbiota. $\mathrm{Mr}^{+}$ or $\mathrm{Mr1}^{-1-} \mathrm{Tap}^{-1-} \mathrm{Ii}^{-1-}$ SPF mice are shown as controls. (B) Normalized $\mathrm{V} \alpha 19-J \alpha 33$ mRNA expression in the MLNs of B6, PWK, CAST, F1 (B6 $\times$ CAST), and N2 (F1 × B6). (C) Manhattan plot of SNP call significance $\left(-\log _{10}[P]\right)$ of MAIT hi versus $\mathrm{MAIT}^{10}(\mathrm{BC} 2$ or $\mathrm{BC} 3)$ ordered by chromosomal location. (D) Normalized $V \alpha 19-J \alpha 33$ mRNA expression in the MLNs of F2 (F1 $\times$ F1) mice, grouped by genotype of the MAIT locus: B6/B6, Het, CAST/CAST. (E) Genomic map of the chromosome 14 TCR- $\alpha$ region encompassing the MAIT CAST locus (boxed).
1D). The results fully confirmed the linkage analysis and indicate a strong gene-dosage effect.

Increased frequency of MAIT-specific iTCR- $\alpha$ rearrangement in CAST mice. As only 1 locus was involved in the MAIT ${ }^{\mathrm{CAST}}$ phenotype, we generated a B6-MAIT ${ }^{\mathrm{CAST}}$ congenic strain that would have a high number of MAITs on a B6 background by backcrossing the MAIT ${ }^{\mathrm{CAST}}$ trait to $\mathrm{B} 6$ for more than 10 generations. The additional recombinants generated during this process allowed us to narrow down the MAIThi locus to the TCR- $\alpha$ region (Table 1 ). This 0.6-Mb region does not include the iV $\alpha 19$ (TRAV1)segments, but encompasses the $3^{\prime}$ end of the V $\alpha$ locus, TCR- $\delta$, J $\alpha$, and $C \alpha$ segments (Figure 1E). This TCR- $\alpha$ location suggested that the higher frequency of MAITs found in the CAST strain might be related to an increased generation of the $\mathrm{iV} \alpha 19-\mathrm{J} \alpha 33$ rearrangements.

Since MAITs do not accumulate in the thymus (see ref. 32 and below), the increased generation of the iV $\alpha 19-J \alpha 33$ rearrangement was consistent with the higher frequency of iV $\alpha 19$ transcripts in the thymus of CAST mice in comparison with B6 (Figure $2 A)$. This hypothesis is further supported by the strict segregation of the iV $\alpha 19$ levels in the thymus of the F2s according to the MAIT locus genotype (Figure 2A). To determine whether expression of the MAIT ${ }^{\text {CAST }}$ trait by hematopoietic cells was sufficient to increase MAIT frequency, T cell-depleted BM from B6-MAIT ${ }^{\mathrm{B} 6}$ or B6-MAIT ${ }^{\text {CAST }}$ mice was used to reconstitute irradiated CD45.1 congenic mice. In these chimeras, the presence of the MAIT ${ }^{\text {CAST }}$ trait in the hematopoietic compartment resulted in increased MAIT frequency in the different organs (Figure 2B), indicating that the MAIT ${ }^{\mathrm{CAST}}$ phenotype is hematopoietic intrinsic.

To better investigate the mechanisms leading to the increased rate of V $\alpha 19-J \alpha 33$ usage, we quantified the usage of the different $\mathrm{V} \alpha$ and $\mathrm{J} \alpha$ segments in the thymus of B6, BALB/c, and CAST strains. We used a 5' RACE TCR- $\alpha$ amplification step followed by deep sequencing (42). Because the $\mathrm{V} \alpha$ segments rearrange to the $\mathrm{J} \alpha$ segments in a sequential and orderly fashion beginning with the most $3^{\prime} \mathrm{V} \alpha$ and $5^{\prime} \mathrm{J} \alpha$ segments and the $\mathrm{V} \alpha 19$ segment is the most 5', the frequency of the iV $\alpha 19-\mathrm{J} \alpha 33$ rearrangements might be proportional to the usage of the most distal ( $\left.5^{\prime}\right) \mathrm{V} \alpha$ segments. We indeed observed a much higher usage of the distal V $\alpha$ segments in CAST mice as compared with B6 mice (Figure 2C), while no difference was found with regards to J $\alpha$ usage (Supplemental Figure 2A). The increased usage of distal $\mathrm{V} \alpha$ segment in CAST could result from the lack of a $\mathrm{V} \alpha$ triplication that is exclusively present in $\mathrm{B} 6$ mice (Figure 2C and ref. 43). Hence, we quantified the $\mathrm{V} \alpha$ segments in thymocytes from BALB/c mice, which also lack this triplication: the distal V $\alpha$ usage was slightly increased, but did not reach CAST levels (Figure 2C), in agreement with MAIT iTCR- $\alpha$ frequency 
A

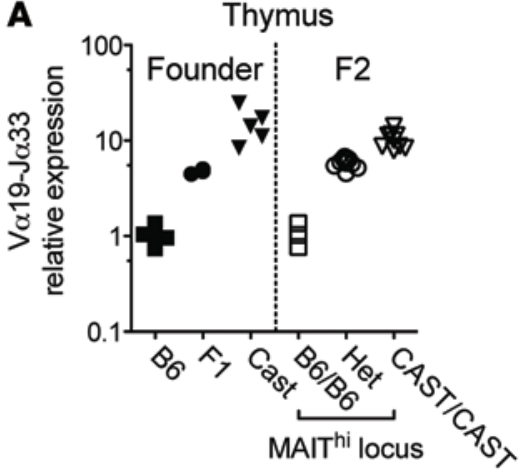

B



c
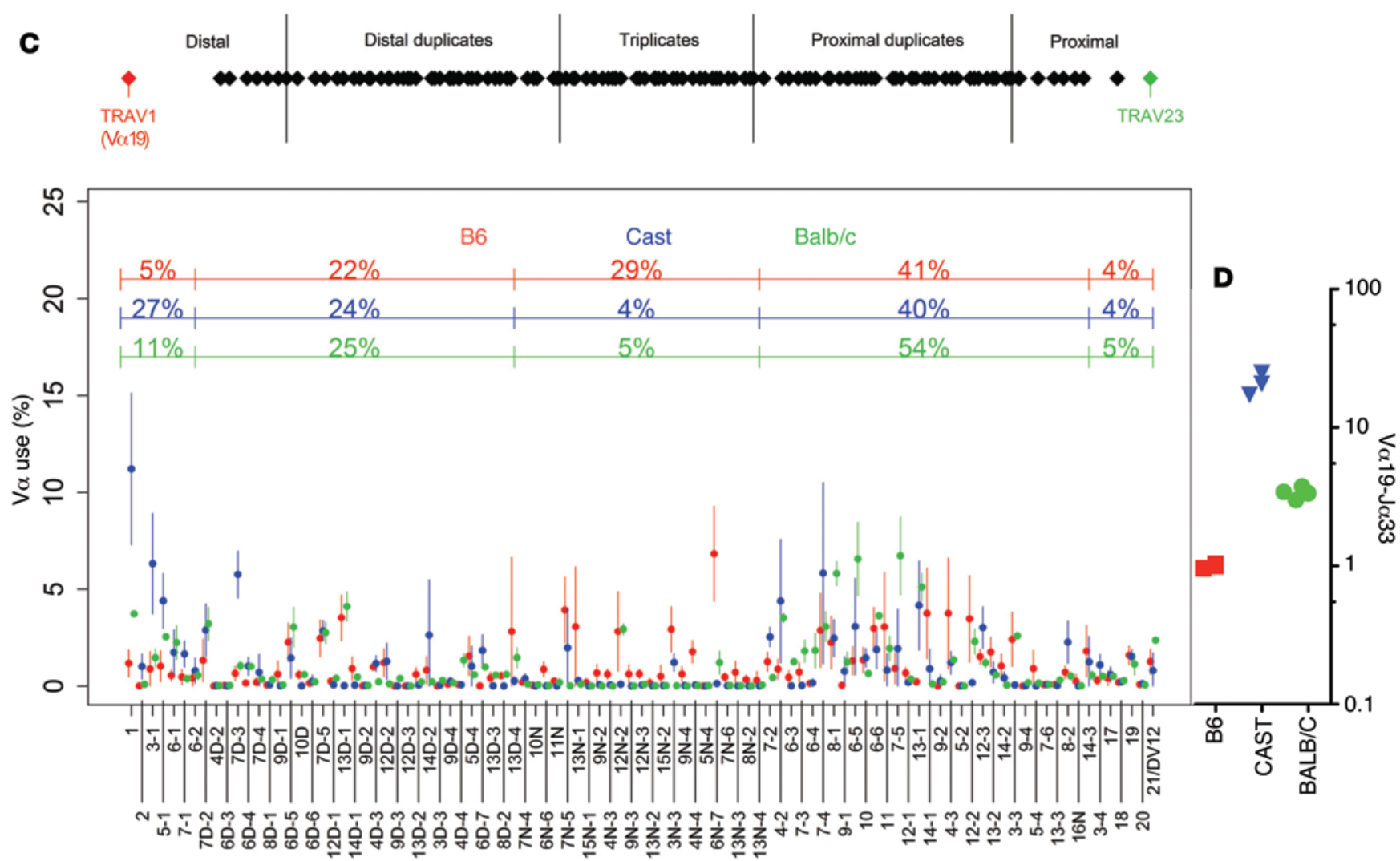

$\mathbf{E}$



Figure 2. The MAIT ${ }^{\text {CAST }}$ locus determines iVo19 levels in the thymus, is hematopoietic intrinsic, and leads to an increased usage of the distal Vo segments. (A) Normalized V $\alpha 19-J \alpha 33$ mRNA levels in the thymus of the indicated mice. (B) Normalized V $\alpha 19-J \alpha 33$ mRNA levels in irradiated B6 recipients 60 days after reconstitution by T cell-depleted BM from B6-MAIT ${ }^{B 6}$ (B6) or B6-MAIT ${ }^{\text {CAST }}$ (CAST) donors. (C) Top: map of the TCR-V $\alpha$ locus. Bottom: $V \alpha$ segment usage by thymocytes from the indicated mice (mean \pm SD) (2-3 individual mice of each genotype were studied). (D) Normalized V $\alpha 19-J \alpha 33$ mRNA levels in the thymus of the indicated mice. (E) The effect of the MAIT ${ }^{\text {CAST }}$ locus is chromosome 14 intrinsic: the V $\alpha 19+9^{+}$TCR- $\alpha$ s were sequenced in thymocytes from F1 (B6 × CAST) mice. Their B6 or CAST origin was determined according to 2 polymorphic nt in the Va19 segment. B6 and CAST mice were used as controls. 

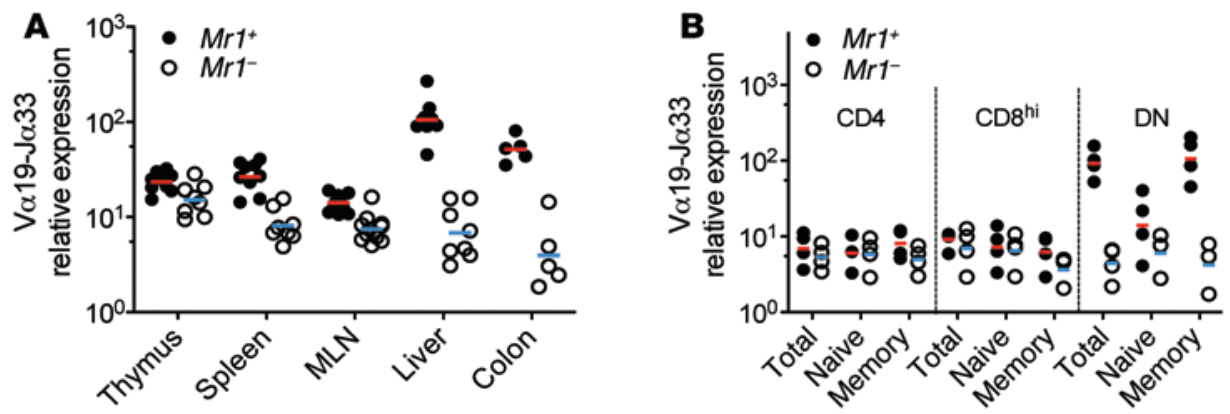

C


Figure 3. MAITs in Rorcgt-GFP'C B6-MAI$\mathrm{T}^{\text {CAST }}$ mice are GFP+CD44 ${ }^{\text {hi }} D N / C D 88^{10}$. (A) Normalized V $\alpha 19$-Ja33 mRNA expression in the indicated organs from $\mathrm{Mr}^{+}$or $\mathrm{Mr1}^{-1-}$ B6-MAIT ${ }^{\text {CAST }}$ mice. (B) Normalized V $\alpha 19$ Ja33 mRNA levels in the indicated subsets isolated from pooled spleen and MLNs. $\mathrm{CD}^{+}{ }^{+}\left(\mathrm{CD}_{4}{ }^{+} \mathrm{CD} 8^{-}\right), \mathrm{CD}^{\mathrm{hi}}\left(\mathrm{CD} 4^{-} \mathrm{CD} 8^{\mathrm{hi}}\right), \mathrm{DN}$ (CD4-CD8 ${ }^{\text {lo/neg }}$, total (unseparated), naive (CD44 ${ }^{10}$ ), and memory (CD44hi) cells are shown. Each dot represents an independent sort from pools of 2 to 5 mice studied in 5 independent experiments. (C) Gating strategy and staining (left, liver) and frequency (right) in the indicated organs of TCR- $\beta^{+}$Thy $1.2^{+}$CD1d- $\alpha$ CC-Tet ${ }^{\text {neg }}$ FFP $^{+} C D 4^{+}$ CD8 ${ }^{\text {hi }}$ or DN (CD4-CD8 ${ }^{\text {lo/neg }}$ ) cells in RorcgtGFP ${ }^{T C}$ B6-MAIT ${ }^{\text {CAST }}$ mice. Representative of 3 independent experiments with 3 to 5 mice per group. For skin and lungs, 6 mice in each group were studied in 1 experiment. (D) Normalized V $\alpha 19-J \alpha 33$ mRNA levels in FACS-sorted TCR$\beta^{+}$Thy $1.2^{+} C^{2} 4^{\text {neg }} C D 8^{\text {lo/neg }} C^{2} 44^{\text {hi }} \mathrm{CFP}^{+}$cells (black circles) and GFP- cells (white circles) from the MLNs and spleen of Rorcgt-GFP ${ }^{T C}$ B6-MAIT ${ }^{\text {CAST }}$ (CAST/CAST, CAST homozygote; Het, heterozygote; for the MAIT locus), Rorcgt-GFP ${ }^{T C} \mathrm{~B} 6-\mathrm{MAIT}{ }^{\mathrm{B} 6}$ (B6/B6), or Rorcgt-GFP TC B6 (B6) mice. Each dot represents an independent sort from pools of 2 to 5 mice.

Altogether, these results further argue against the involvement of disparities in DP thymocyte life span or other cell biology processes between the 2 strains that would explain the high MAIT frequency in CAST mice. Differences in the molecular mechanism of the $\mathrm{V} \alpha$ to $\mathrm{J} \alpha$ recombination between B6 and CAST strains are certainly involved.

Identification and tissue distribution of MAITs in B6-MAIT CAST

(Figure 2D): MAIT iTCR- $\alpha$ frequency was $3.4 \pm 0.3 \mathrm{AU}$ in BALB/c as compared with $1.03 \pm 0.26$ in B6 (Figure 2D). Altogether, these results suggest that a higher usage of distal $\mathrm{V} \alpha$ segments contributes to the higher frequency of MAITs observed in CAST mice.

The origin of the higher use of the distal $\mathrm{V} \alpha$ segments in CAST is not clear. The mapped region includes part of the $3^{\prime}$ UTR of Dad1, a gene with antiapoptotic function (Figure 1E). Because any decrease of the life span of the $\mathrm{CD} 4^{+} \mathrm{CD} 8^{+}(\mathrm{DP})$ thymocytes leads to a decrease in the use of the V $\alpha 19$ segment (44), we quantified Dad1 mRNA in B6 and CAST mice and observed similar expression (Supplemental Figure 2B). We also did not find any differences in the recombination signal sequences of the Ja33 segments between B6 and CAST (45). Notably, the higher rate of Va19-Ja33 rearrangements found in CAST was chromosome intrinsic. Indeed, in B6/CAST F1 thymocytes, more than $80 \%$ of the V $\alpha 19^{+}$TCR- $\alpha$ transcripts were encoded by the CAST chromosome (Figure 2E). congenic mice. The increased number of MAITs in B6-MAIT ${ }^{\text {CAST }}$ congenic mice allowed us to further characterize their tissue distribution and phenotype. Using RT-qPCR, we quantified MAITs in the different organs of B6-MAIT ${ }^{\mathrm{CAST}}$ mice on an $\mathrm{Mr}^{+}$or $\mathrm{Mr}^{\text {neg }}$ background. In $\mathrm{MrI}^{+}$thymus, the amount of $\mathrm{iV} \alpha 19$ transcripts was higher $(23.9 \pm 5.5 \mathrm{AU}$ ) than in B6 or BALB/c (Figure 2, A and D, and Figure 3A). Notably, the iV $\alpha 19$ levels were barely decreased on an $\mathrm{Mr}^{\text {neg }}$ background, further confirming that MAITs do not accumulate in the thymus. In the periphery, MAITs were abundant in the liver, with a strong difference between $\mathrm{Mrl}^{+}$and $\mathrm{MrI}^{-}$ mice (117 $\pm 62 \mathrm{AU}$ versus $8.1 \pm 5.2 \mathrm{AU}$ ) (Figure $3 \mathrm{~A})$. A similar pattern was observed in the colon LP $(53 \pm 17 \mathrm{AU}$ versus $5.3 \pm 5.2$ $\mathrm{AU})$. The iV $\alpha 19$ levels in the MLNs (14.4 $\pm 2.7 \mathrm{AU})$ and spleen (28 $\pm 9.3 \mathrm{AU}$ ) (Figure 3A) were not significantly different from the levels observed in the thymus. Nevertheless, the absence of MR1 expression resulted in slightly lower iVa19 levels in these latter 
A
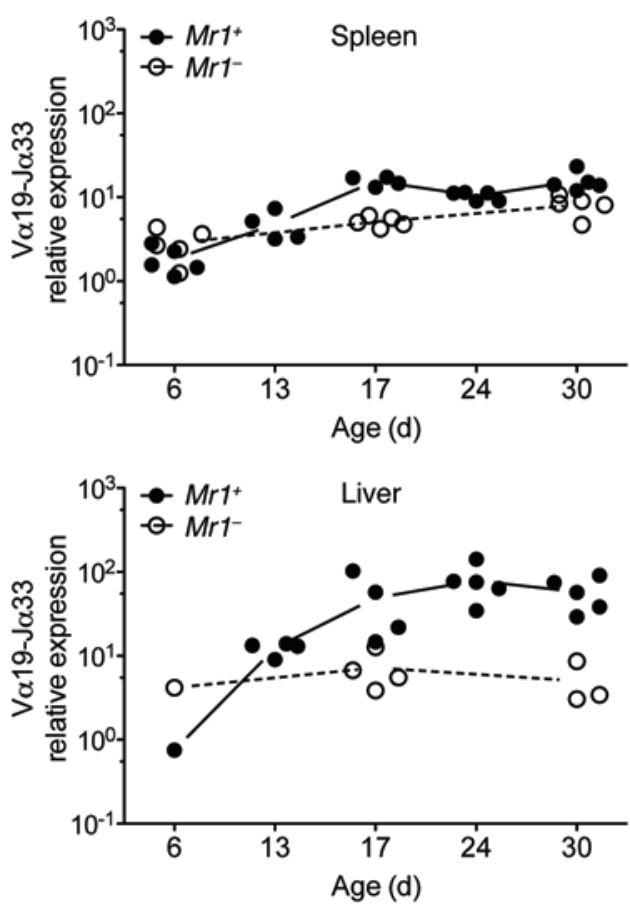

C

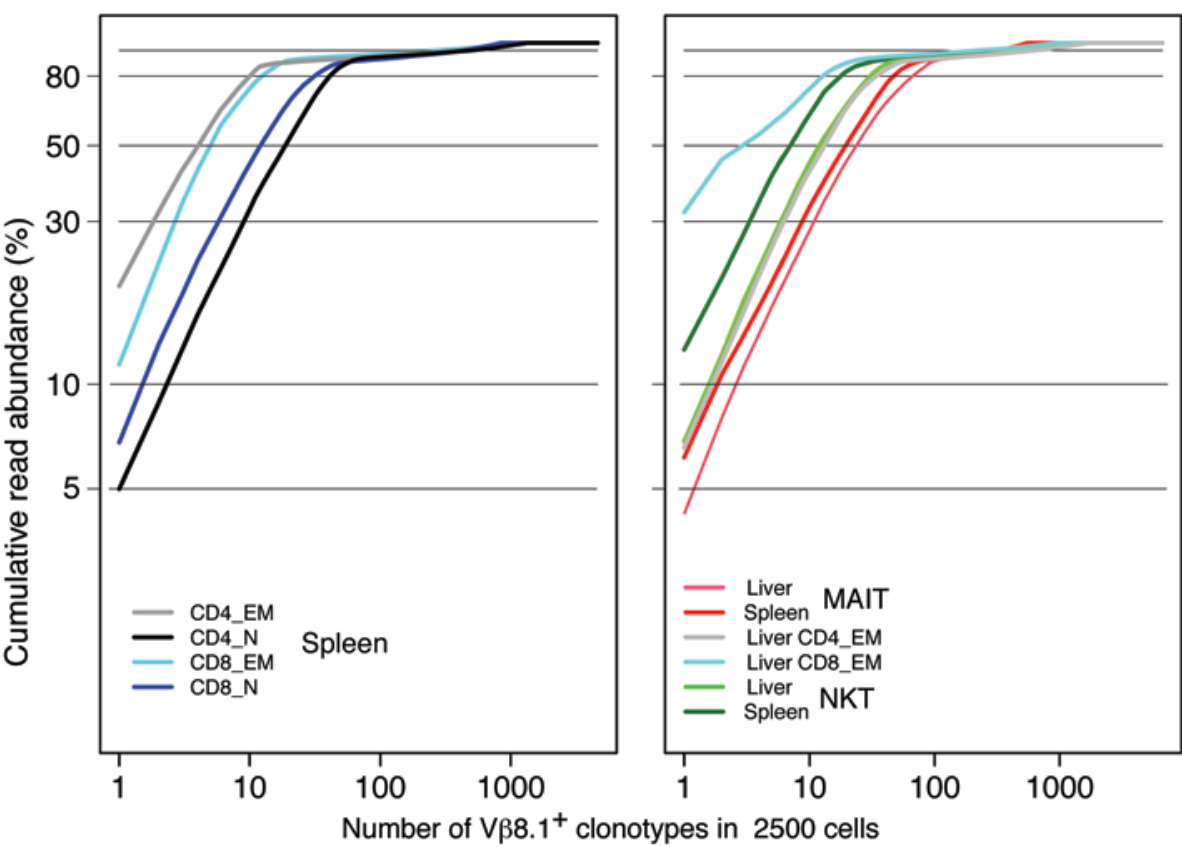

B
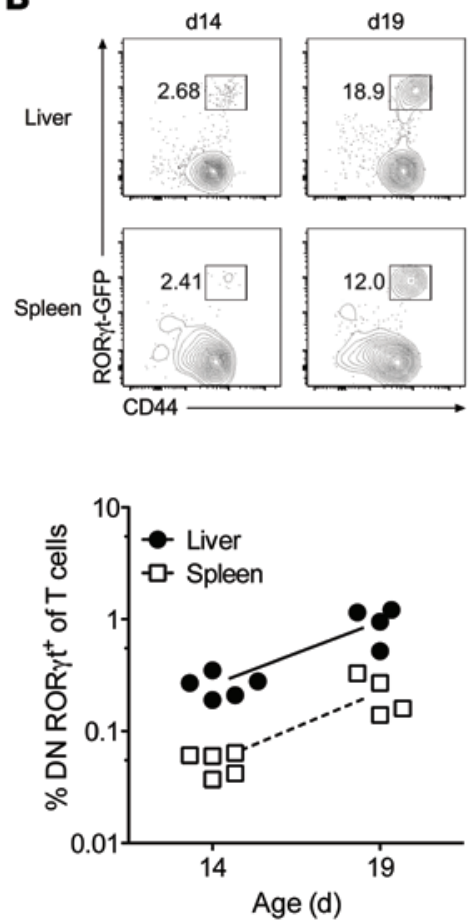

D

organs (8.72 $\pm 3.7 \mathrm{AU}$ and $7.8 \pm 3 \mathrm{AU}$, respectively). Thus, in mice, although MAITs do not significantly accumulate in the peripheral lymphoid organs, they are still more abundant in the liver and colon, as observed in humans. However, the overall number of MAITs in mice was much lower than in humans, suggesting that mouse MAITs do not considerably expand in the periphery.

The poor peripheral accumulation might be related to differences in naive/memory status of mouse versus human MAITs, as we have previously observed that MAITs from VB6 $\mathrm{Tg}$ and $\mathrm{Tap}^{-1-}$ $I i^{-/}$mice display a naive $\left(\mathrm{CD} 44^{10}\right)$ phenotype (32). We therefore
Figure 4. Development of MAITs after birth and TCR- $\beta$ repertoire analysis of mouse MAITs. (A and B) Quantitation of MAITs by (A) RT-qPCR or (B) flow cytometry in the indicated organs at different time points after birth. Dot plots are gated on DNCD8 ${ }^{10}$ T cells. (C and $\mathbf{D}$ ) The indicated mouse cell subsets were FACS sorted from RorcgtGFP ${ }^{T C}$ B6-MAIT ${ }^{\text {CAST }}$ mice, and V $\beta 8.1$ TCR- $\beta$ repertoire analysis was performed by deep sequencing. The cumulative frequency of productive TCR- $\beta$ rearrangement is plotted for individual clonotypes ranked according to decreasing frequency. (C) Naive (CD62L${ }^{\text {hi }} \mathrm{CD} 44^{10}$ ) and memory (CD62 $\left.{ }^{\text {lo }} \mathrm{CD} 44^{\mathrm{hi}}\right) \mathrm{CD}^{+}$ or $\mathrm{CD}^{+}$subsets were included as controls. (D) Control populations, NKT (CD1d- $\alpha \mathrm{CC}-$ $\mathrm{Tet}^{+}$), and MAIT (CD4 $\left.{ }^{\text {nes }} \mathrm{CD}^{\text {lo/neg }} \mathrm{CD} 4^{\text {hi }}{ }^{\mathrm{C}} \mathrm{FP}^{+}\right)$ from the indicated organs were analyzed. Two to three (except for the liver) replicates were studied for each condition, and representative results are shown. Analysis of $V \beta 8.2$ TCR- $\beta$ segments showed similar results (not depicted).

sorted $\mathrm{T}$ cells from the spleen and the MLNs of B6-MAIT ${ }^{\text {CAST }}$ congenic mice according to CD4/CD8 and CD44 expression and quantified the iVa19 transcripts. The iV 19 mRNA was found mostly in $\mathrm{DN}, \mathrm{CD} 8^{\mathrm{lo}}$, and $\mathrm{CD} 44^{\mathrm{hi}}$ fractions (Figure 3B), indicating that mouse MAITs are $\mathrm{CD} 4^{\text {neg }}$ $\left(\mathrm{DN} / \mathrm{CD} 8^{\mathrm{lo}}\right)$ and display a CD $44^{\mathrm{hi}}$ memory phenotype as in humans. The absence of $C D 8 \alpha \beta^{\text {hi }}$ expression by mouse MAITs is consistent with the CD $8 \alpha \beta^{\text {lo }}$ and $C D 8 \alpha \alpha / D N$ phenotype of human adult MAITs $(21,22,32)$.

Until MR1 tetramers become widely available, mouse MAIT study will remain hampered by the lack of specific markers, as there is no mouse equivalent to human CD161 or another surface marker that would be specific for MAITs. Because all human MAITs express the transcription factor ROR $\gamma \mathrm{t}(21,24)$, we introgressed a Rorcgt-GFP $P^{T G}$ reporter $\mathrm{Tg}$ (46) into B6-MAIT ${ }^{\text {CAST }}$ congenic mice based on the hypothesis that most $\mathrm{GFP}^{+}$cells in the $\mathrm{DN} / \mathrm{CD} 8^{\text {lo }} \mathrm{T}$ cell subsets would be MAITs. The number of CD $44^{\text {hi }} \mathrm{GFP}^{+}$cells in the $\mathrm{CD} 8^{\text {hi }}$ or $\mathrm{CD}_{4}^{+}$subsets did not vary significantly in $\mathrm{Mr}^{+}$versus $\mathrm{Mr1}^{-/}$backgrounds (Figure 3C). In contrast, an MR1-dependent subset of $\mathrm{CD} 44^{\mathrm{hi}} \mathrm{GFP}^{+} \mathrm{DN} / \mathrm{CD} 8^{\mathrm{lo}} \mathrm{T}$ cells was observed in the different organs of B6-MAIT ${ }^{\text {CAST }}$ mice, with higher frequencies in nonlymphoid tissues such as liver, lung, skin, and gut LP than in lymphoid organs, including spleen and MLNs (Figure 3C).

To verify that $C D 44^{\text {hi }} \mathrm{GFP}^{+} \mathrm{DN} / \mathrm{CD} 8^{\text {lo }} \mathrm{T}$ cells are mostly MAITs in $\mathrm{Mr}^{+}$Rorcgt-GFP ${ }^{T G}$ B6-MAIT ${ }^{\text {CAST }}$ mice, iV 119 chain mRNA 
was quantified in spleen T cells from $\mathrm{MrI}^{+}$and $\mathrm{MrI}^{-/-}$mice sorted according to GFP, CD44, and CD4/CD8 expression. iVa19 expression was MR1-dependent and strongly correlated with ROR $\gamma$ t-GFP expression (Figure 3D). The level of iV $\alpha 19$ mRNA in GFP-expressing CD $44^{\mathrm{hi}} \mathrm{DN} / \mathrm{CD} 8^{\text {lo }}$ cells from MR1-sufficient B6-MAIT ${ }^{\text {CAST }}$ mice $(1783 \pm 908 \mathrm{AU})$ was 90 times higher than in the GFP-negative counterparts and 280 times higher than in MR1-deficient B6-MAIT ${ }^{\mathrm{CAST}}$ mice $\left(6.4 \pm 4.3 \mathrm{AU}\right.$ for $\mathrm{GFP}^{+}$and $3 \pm$ 1.3 AU for $\mathrm{GFP}^{-}$cells) (Figure 3D). This pattern of $\mathrm{iV} \alpha 19$ expression also occurs in B6-MAIT ${ }^{\mathrm{B} 6}$ or B6 mice (350-fold higher in $\mathrm{CD} 44^{\text {hi }} \mathrm{GFP}^{+} \mathrm{DN} / \mathrm{CD}^{\text {lo }} \mathrm{T}$ cells from $\mathrm{MrI}^{+}$than from $\mathrm{MrI}^{-/-}$mice) (Figure 3D). The iVa19 mRNA levels found in CD $44^{\text {hi }} \mathrm{GFP}^{+} \mathrm{DN} /$ $\mathrm{CD}^{\text {lo }} \mathrm{T}$ cells from $\mathrm{Mr}^{+}$Rorcgt-GFP ${ }^{T G} \mathrm{~B} 6$-MAIT ${ }^{\mathrm{CAST}}$ mice $(1,000$ times higher than in unseparated MLN cells from B6 mice and 10 times higher than in MLN cells from $\mathrm{V} \beta 6 \mathrm{Tg} \mathrm{Tap}^{-/-} \mathrm{Ii}^{-/-}$mice) indicate that $80 \%$ to $100 \%$ of these cells were MAITs. These results show that in mice as in humans, most, if not all, MAITs display a $\mathrm{CD} 44^{\text {hi }} \mathrm{GFP}^{+} \mathrm{DN} / \mathrm{CD} 8^{\text {lo }}$ phenotype.

Expansion versus accumulation of MAITs in mice. In humans, MAITs are very few in the thymus and cord blood $(21,22)$ and expand after birth to reach high clonal size $(20,33)$. To determine the dynamics of MAITs after birth in mice, we quantified the iV $\alpha 19$ transcripts at 6 to 30 days of age in the thymus, spleen, and liver of $\mathrm{MrI}^{+}$or $\mathrm{Mr1}^{-/-}$Rorcgt-GFP ${ }^{T G}$ B6-MAIT ${ }^{\mathrm{CAST}}$ mice. In the spleen and liver, the MAIT frequency was very low in neonates (day 6) and progressively increased after day 13 to day 17 (Figure 4A). We did not observe any accumulation of MAITs in the thymus, as the difference in $\mathrm{iV} \alpha 19$ levels between $\mathrm{MrI}^{+}$and $\mathrm{Mr1}^{-/-}$mice was less than 2-fold at all time points (Supplemental Figure 3 for young and Figure $3 \mathrm{~A}$ for adult mice). To determine whether MAITs appearing in young mice express ROR $\gamma \mathrm{t}$, we measured GFP ${ }^{\text {hi }} C D 44^{\text {hi }} \mathrm{DN} / \mathrm{CD} 8^{\text {lo }} \mathrm{T}$ cell frequency in the spleen and liver 14 and 19 days after birth (Figure 4B). The frequency of MAITs (GFPhi CD $44^{\text {hi DN} / C D 8} 8^{\text {lo }}$ T cells) increased by 3 - to 4 -fold between these 2 time points, in accordance with iV $\alpha 19$ mRNA quantitation. Together, these results indicate that MAITs do not accumulate in the thymus, as previously suggested by the study of TCR Tg mice and human thymus $(21,32)$. After birth and up to weaning time, MAIT frequency in the spleen and liver gradually increased to represent approximately $0.1 \%$ and $1 \%$ of total T cells, respectively (Figure 4B).

The increased frequency of MAITs observed in the liver could be related either to peripheral proliferation or to an accumulation of MAITs in this organ. In the first hypothesis, the TCR- $\beta$ repertoire should be less diverse than in the second, as the clonal size would be higher in the case of proliferation. We therefore analyzed the diversity of the MAIT TCR- $\beta$ chains using V $\beta$ segmentspecific primers in PCRs followed by deep sequencing. The MAIT $\left(\mathrm{CD} 44^{\mathrm{hi}} \mathrm{GFP}^{+} \mathrm{DN} / \mathrm{CD}^{\mathrm{lo}}\right)$ repertoire was compared with that of NKT (CD1d- $\alpha$ GC-Tet $\left.{ }^{+}\right)$, effector memory (EM) $\left(C D 44^{\text {hi }}\right.$ CD62L $\left.{ }^{\text {lo }}\right)$, and naive $\left(\mathrm{CD} 44^{\mathrm{lo}}\right) \mathrm{CD} 4^{+}$or $\mathrm{CD} 8^{+} \mathrm{T}$ cells. The analysis of the rarefaction curves (plots relating the cumulative frequency of individual clonotypes ranked by decreasing frequency) of $\mathrm{V} \beta 8.1^{+} \mathrm{T}$ cells from the spleen and liver showed that, although using specific V $\beta$ segments, mouse MAITs harbor a rather diverse repertoire, similar in diversity to that of NKT cells, without real oligoclonality (Figure 4, C and D). Similar data were obtained with a VB8.2- specific primer (data not shown). Together, these results indicate that murine MAITs do not extensively proliferate in the periphery and that the higher proportion of MAITs found in the liver is the result of accumulation rather than proliferation.

Phenotype and functionality of mouse MAITs. Rorcgt-GFP TG B6-MAIT ${ }^{\text {CAST }}$ mice harbor sufficient numbers of GFP-tagged MAITs to enable the analysis of their phenotype and functionality. We found that MAITs isolated from the spleen and liver express high levels of IL-7R $\alpha$ (CD127), IL-18R $\alpha$, and IL-12R $\beta 1$ (CD212), as their human counterparts do (Figure 5A, Supplemental Figure 4A, and ref. 21), whereas the IL-2R (CD122) chain was not detectable. A subpopulation of spleen MAITs expressed NKG2D, while NK1.1 expression was only found on a subset of MAITs from the liver. CD26, a dipeptidase highly expressed by human MAITs, was expressed by most mouse MAITs (Figure 5B). CD103 was detected on a substantial percentage of spleen MAITs, indicating their tissue tropism. In line with this, mouse MAITs did not express CCR7 and many are CCR6 ${ }^{+}$. A subpopulation of liver MAITs expressed CXCR6. CCR5 expression was not detected. In summary, naturally occurring mouse MAITs are very similar to their human counterparts and express several markers distinguishing them from conventional T or NKT cells, including ROR $\gamma \mathrm{t}, \mathrm{IL}-18 \mathrm{R} \alpha$, and CCR6.

Importantly, all MAIT $\left(\mathrm{CD} 44^{\mathrm{hi}} \mathrm{GFP}^{+} \mathrm{DN} / \mathrm{CD} 8^{\mathrm{lo}}\right)$ cells from $\mathrm{Mr1}^{+}$B6-MAIT ${ }^{\mathrm{CAST}}$ mice expressed the transcription factor ZBTB16 (PLZF), as observed in humans (Figure 5C and ref. 31). In contrast, ZBTB16 was expressed by only a small proportion (approximately $3 \%$ ) of the $\mathrm{V} \beta 6 / 8^{+} \mathrm{DN} \mathrm{T}$ cells found in $\mathrm{iV} \alpha 19 \mathrm{Tg}$ mice (Supplemental Figure 4B) despite the fact that more than $50 \%$ of these cells are bacterial reactive and MR1 restricted (6, 32). These results probably explain the lack of $Z b t b 16$ detection by RT-qPCR in our previous report that examined Zbtb16 levels in $\mathrm{CD}^{+}$and $\mathrm{DN} \mathrm{T}$ cells isolated from $\mathrm{iV} \alpha 19 / \mathrm{V} \beta 6$ double-Tg mice (32). In addition, $100 \%$ of the $\mathrm{GFP}^{+}$cells found in the DN T cell subset from V $\beta 6$ Tg B6-MAIT ${ }^{\text {CAST }}$ mice expressed ZBTB16 (Supplemental Figure 4C). These results suggest that the premature expression of the iTCR- $\alpha$ chain or saturation of the selecting niches (47) does not allow the acquisition of the full MAIT differentiation program in TCR Tg mice.

To assess the functionality of mouse MAITs, we sorted them together with control populations: mainstream memory (CD44 ${ }^{\mathrm{hi}}$ ) $\mathrm{CD}^{+}$and $\mathrm{CD}^{+} \mathrm{T}$ cells as well as NKT cells (the sorting strategy is shown in Supplemental Figure 5). We then assessed the production of lymphokines after stimulation with anti-CD3/CD28 beads (Figure 5D). We found that MAITs produced small amounts of IFN- $\gamma$, but high levels of TNF- $\alpha$, GM-CSF, and IL-17. Contrary to human MAITs, mouse MAITs secreted measurable amounts of IL-4 and IL-10 and low levels of IL-5. This particular lymphokine

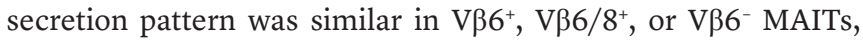
suggesting that the presence of Th2 cytokines was not due to a contamination by type 1 NKT cells, which do not express the V $\beta 6$ segment. However, the presence of type 2 NKT cells could not be completely excluded, since they harbor a diverse TCR- $\beta$ repertoire and do not bind CD1d- $\alpha$ GC tetramers. We therefore repeated this experiment using $\mathrm{GFP}^{+} \mathrm{CD} 44^{+} \mathrm{DN} / \mathrm{CD} 8^{\text {lo }} \mathrm{T}$ cells from $\mathrm{Cd}_{1 d^{-/}}$B6-MAIT ${ }^{\mathrm{CAST}}$ mice that are devoid of any kind of NKT cells. Importantly, the frequency of $\mathrm{GFP}^{+} \mathrm{CD} 44^{+} \mathrm{DN} / \mathrm{CD} 8^{\text {lo }}$ 
A
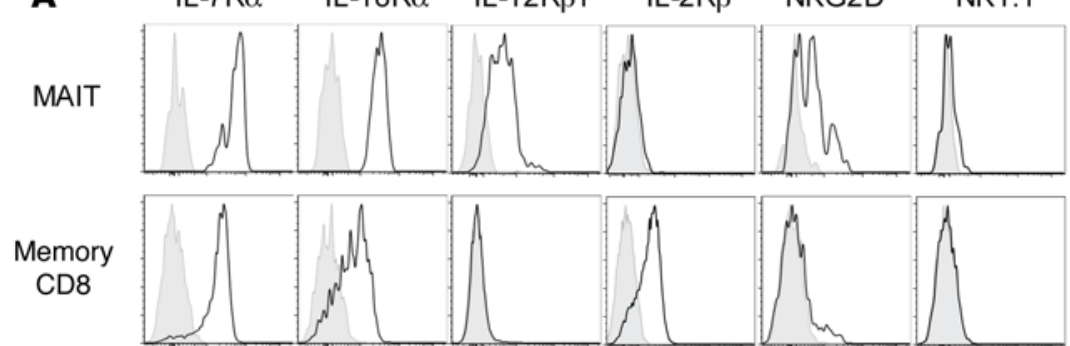

NKT

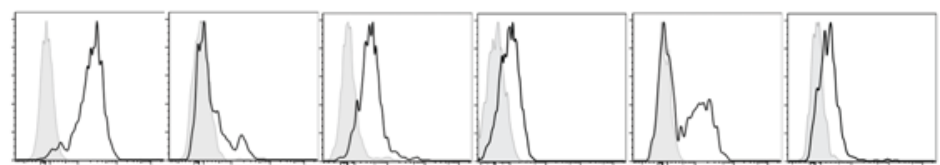

$\begin{array}{llllll}\text { CD26 } & \text { CD103 } & \text { CCR5 } & \text { CCR6 } & \text { CXCR6 } & \text { CCR7 }\end{array}$
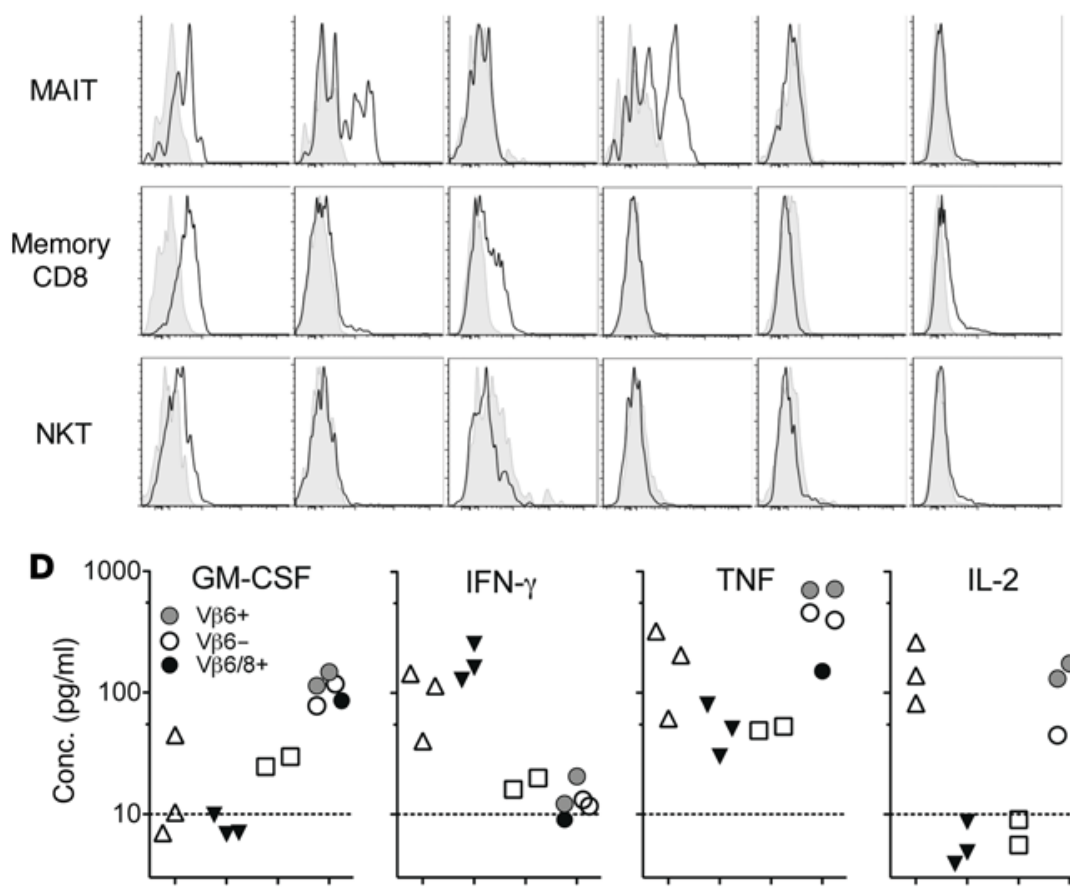

IL-2
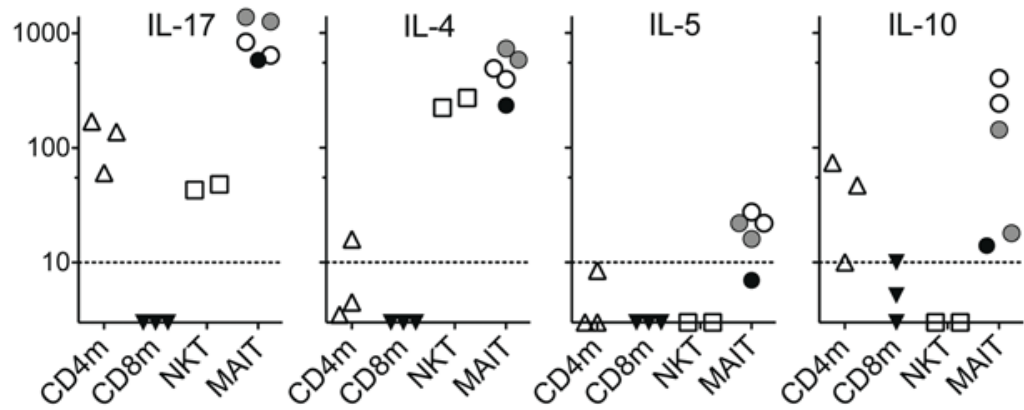
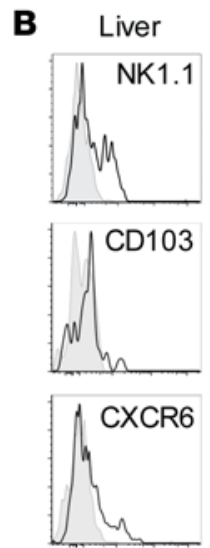

C



Figure 5. Phenotype and cytokine production by mouse MAITs. (A and B) Surface expression of the indicated markers was analyzed on Thy1.2+TCR- $\beta^{+} T$ cells from the (A) spleen or (B) liver of Rorcgt-GFP TC B6-MAIT ${ }^{\text {CAST }}$ mice. The indicated subsets were studied: MAITs (DN/CD8 $\left.{ }^{\circ} \mathrm{CD}_{4}{ }^{+} \mathrm{GFP}^{+}\right)$, memory CD8 ${ }^{+} \mathrm{T}$ cells (CD8 ${ }^{\text {hi }}$ CD44 ${ }^{+}$), and NKT cells (CD1d- $\alpha$ CC-Tet ${ }^{+}$). Shaded histograms show isotype or FMO control (CD103). Representative of at least 3 experiments. (C) Expression of PLZF and ROR $\gamma \mathrm{t}-\mathrm{GFP}$ by DN/CD8 ${ }^{\circ} \mathrm{CD} 1 \mathrm{~d}-\alpha \mathrm{CC}-$ Tet $^{-}$TCR- $\beta^{+}$T cells from $\mathrm{Mr}^{+/+}$or $\mathrm{Mr1}^{-/-}$Rorcgt-CFP ${ }^{T C}$ B6-MAIT ${ }^{\text {CAST }}$ mice. (D) Cytokine secretion by MAITs in comparison with control populations. T cells from the spleen of Rorcgt-GFP ${ }^{T C}$ B6-MAIT ${ }^{\text {CAST }}$ mice were identified as Thy $1.2^{+}$TCR $-\beta^{+}$cells, and memory (CD44 $4^{+}$CD4+ or $\mathrm{CD}^{+}$, MAIT (DN/CD8 $\left.{ }^{\text {lo }} \mathrm{CD}_{4} 4^{+} \mathrm{CFP}^{+}\right)$, and NKT (CD1d- $\alpha-$ CC-Tet ${ }^{+}$) subsets were FACS sorted. Eight-thousand cells from each sorted $T$ cell subset were cultured with anti-CD3/28 beads (1:1) for 42 to 45 hours and the cytokine content measured in the culture supernatant. The results were derived from 4 to 7 separate cultures collected over 3 independent experiments. Each dot represents an individual sort. Dashed line indicates quantitation limit. Dots on the $x$ axis indicate not detected.
T cells in $\mathrm{Cd} 1 \mathrm{~d}^{-/-} \mathrm{MrI}^{-/-}$B6-MAIT ${ }^{\mathrm{CAST}}$ mice was extremely low (Supplemental Figure 6, A and B), indicating that more than $90 \%$ to $95 \%$ of the $\mathrm{GFP}^{+} \mathrm{CD} 44^{+} \mathrm{DN} / \mathrm{CD} 8^{\text {lo }} \mathrm{T}$ cells found in $\mathrm{Cd} 1 \mathrm{~d}^{-/-} \mathrm{Mr} \mathrm{I}^{+}$ B6-MAIT ${ }^{\text {CAST }}$ mice are MR1 dependent. MAITs from $\mathrm{Cd} 1 \mathrm{~d}^{-/-} \mathrm{Mr} \mathrm{1}^{+}$ B6-MAIT ${ }^{\text {CAST }}$ mice displayed a pattern of lymphokine secretion (low IFN- $\gamma$, high IL-17, and measurable levels of IL-4 and IL-10; Supplemental Figure 6C) similar to that observed in CD1d- sufficient $\mathrm{Mr}^{+}$B6-MAIT ${ }^{\mathrm{CAST}}$ mice, excluding the possibility that the Th2 cytokines were produced by contaminating NKT cells. Collectively, these data indicate that, in addition to Th1/17 type cytokines, mouse MAITs secrete low amounts of Th2 cytokines. To determine whether Th1/2/17 cytokines were produced by different MAIT subsets or concurrently secreted by a single MAIT, we analyzed IFN- $\gamma$, IL-4, and IL-17 expression by intracytoplas- 
A Gated on TCR $\beta^{+}$DN/CD8 ${ }^{\text {lo }}$ RORyt-GFP ${ }^{+}$

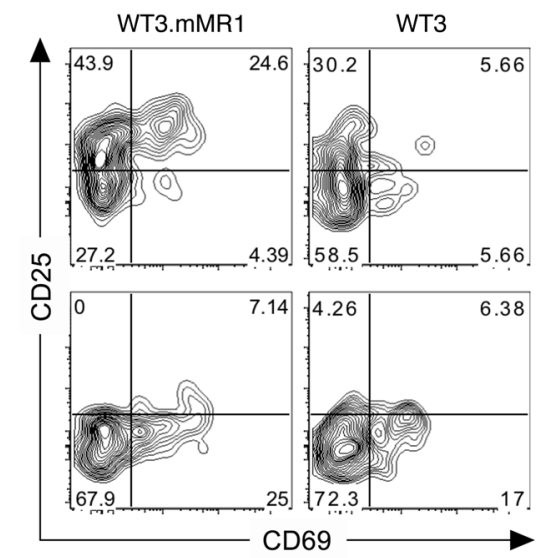

C



B

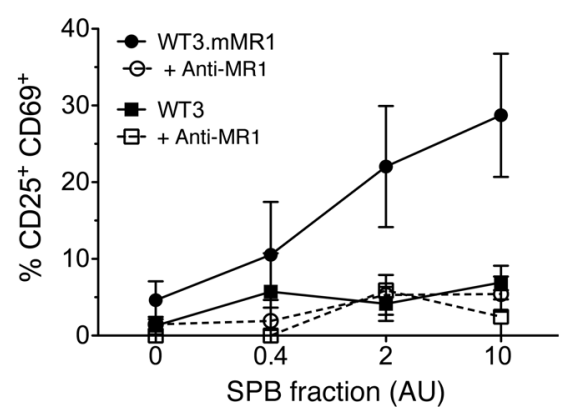

Anti-MR1

$5-\mathrm{A}-\mathrm{RU}$

$(0.93 \mu \mathrm{M})$

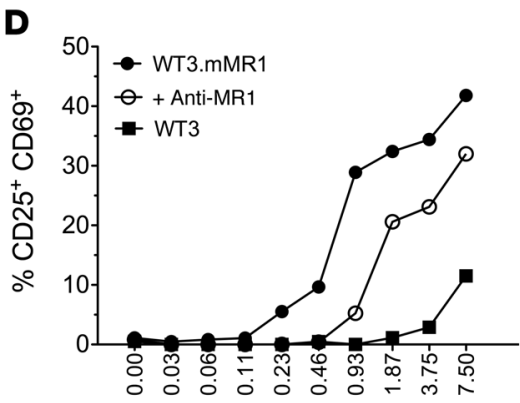

$5-A-R U(\mu M)+M e G$
Figure 6. Natural MAITs are activated by bacteria-derived compound in an MR1-dependent manner. (A) Activation of Rorcgt-GFP ${ }^{T C}$ B6-MAIT ${ }^{\text {CAST }}$ splenocytes after overnight coculture with SPB (2 AU) and WT3 cells overexpressing MR1 (WT3.mMR1) or the parental cell line (WT3). (B) Doseresponse curves of MAIT activation in the presence or absence of anti-MR1 (26.5) blocking antibody. The results were pooled from 3 independent experiments (mean $\pm \mathrm{SD}$ ). (C) Activation of Rorcgt-GFP ${ }^{T C}$ B6-MAIT CAST splenocytes with $0.93 \mu \mathrm{M}$ of $5-\mathrm{A}-\mathrm{RU}$ extemporaneously mixed with $\mathrm{MeG}$ (1:1 ratio) after overnight incubation with WT3 or WT3.mMR1 cells together with anti-MR1 antibdody (bottom panel). (D) Dose-response curves of MAIT activation in the presence or absence of anti-MR1 blocking antibody. Results represent a pool of 3 mice. (C and $\mathbf{D}$ ) Representative of 2 independent experiments.

activated by the SPB fraction, as shown by the upregulation of the activation markers CD69 and CD25 (Figure 6, A and B). This activation was MR1 dependent, since it was blocked by an anti-MR1 antibody (Figure 6, A mic staining of splenocytes after several stimulations, namely, anti-CD3/CD28 beads, PMA/ionomycin, or paraformaldehydefixed (PFA-fixed) E. coli (Supplemental Figure 7). PMA/ionomycin or TCR ligation induced substantial IL-17 expression by MAITs, while IFN- $\gamma$ and IL- 4 were undetectable, in line with the recently published results of cytokine production by MAITs from B6 mice identified with MR1-5-OP-RU tetramers (48). Interestingly, IFN- $\gamma$ was detected in MAITs only after activation with $E$. coli, suggesting that MAITs require additional innate signals to efficiently produce IFN- $\gamma$. Whether Th1/2/17 cytokines are produced by different MAIT subsets remains to be addressed, since we have been unable to define stimulation conditions in which all the cytokines are reliably detectable by intracytoplasmic staining.

To determine whether the presence of MAITs influences antibody production, we measured the serum levels of IgA and IgG isotypes in $\mathrm{MrI}^{+}$and $\mathrm{Mrl}^{-}$B6-MAIT ${ }^{\mathrm{CAST}}$ mice (Supplemental Figure 8). Serum IgA levels were slightly decreased in the absence of MAITs, but the levels of all the other Ig isotypes tested were similar. These results suggest that MAITs are probably not involved in the regulation of systemic humoral responses, but may modify local immune responses.

To further verify the antigen specificity of $\mathrm{GFP}^{+} \mathrm{CD} 44^{\text {hi }} \mathrm{DN} /$ $\mathrm{CD} 8^{\text {lo }} \mathrm{T}$ cells, we measured their activation after stimulation with graded amounts of a MAIT-activating semipurified bacterial fraction (SPB) (49) loaded on MR1-overexpressing WT3 cells (50). We found that MAITs $\left(\mathrm{GFP}^{+} \mathrm{CD} 44^{\mathrm{hi}} \mathrm{DN} / \mathrm{CD} 8^{\mathrm{lo}}\right)$, but not $\mathrm{GFP}^{\mathrm{lo}} \mathrm{C}-$ $\mathrm{D} 44^{\text {hi }} \mathrm{CD}^{+} \mathrm{T}$ cells from the same culture dish, were specifically and B). In line with this, incubation of the SPB fraction with the parental WT3 cell line (which expresses very low levels of MR1) did not activate MAITs. The active compound or compounds in this bacterial fraction derive from the rib biosynthesis pathway $(10,49)$ through a reaction between the rib intermediate 5 -amino6-D-ribityl-uracil (5-A-RU) and methyl-glyoxal (MeG) generating the 5-(2-oxopropylideneamino)-6-D-ribitylaminouracil (5-OP$\mathrm{RU})$ pyrimidine adduct. The 5-OP-RU binds to and is stabilized by MR1 and activates MAITs. We therefore measured the activation of polyclonal MAITs by MR1-overexpressing WT3 cells incubated with serial dilutions of 5-A-RU extemporaneously mixed with MeG. MAITs were activated by this compound when incubated with MR1-overexpressing cells but not the MR1 $1^{10}$ parental cell line (Figure 6C). The activation was also decreased in the presence of an anti-MR1 antibody. These results demonstrate that the $\mathrm{GFP}^{+} \mathrm{CD} 44^{\text {hi }} \mathrm{DN} / \mathrm{CD}{ }^{\text {lo }} \mathrm{T}$ cells found in $\mathrm{Mr}^{+}{ }^{+}$B6-MAIT ${ }^{\mathrm{CAST}}$ mice are bona fide MAITs, recognizing a bacterial ligand derived from the rib biosynthesis pathway in an MR1-dependent manner.

Polyclonal mouse MAITs are protective and migrate to the infection site in an experimental model of UTI. The availability of a MAIT-rich mouse model allowed us to investigate the role of MAITs in antimicrobial immunity. Because we detected MAITs in the urine of 10 out of 12 patients with leukocyturia associated with UTI (Figure 7, A and B), we studied an experimental model of UTI. Female Rorcgt-GFP ${ }^{T G}$ B6-MAIT ${ }^{\mathrm{CAST}}$ mice with $\left(\mathrm{Mr}^{+}\right)$or without MAITs $\left(\mathrm{MrI}^{-/}\right)$were intravesically instilled with uropathogenic E. coli (UPEC) strain UTI89 (51). The lymphoid 
A $\mathrm{CD}^{+} \gamma \delta \mathrm{TCR}^{-} \mathrm{T}$ cells

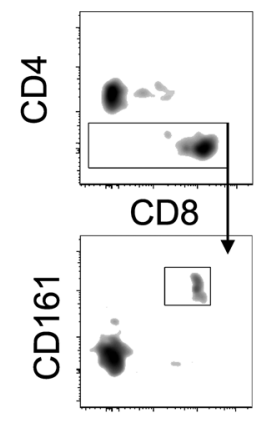

$\vee \alpha 7.2$
B

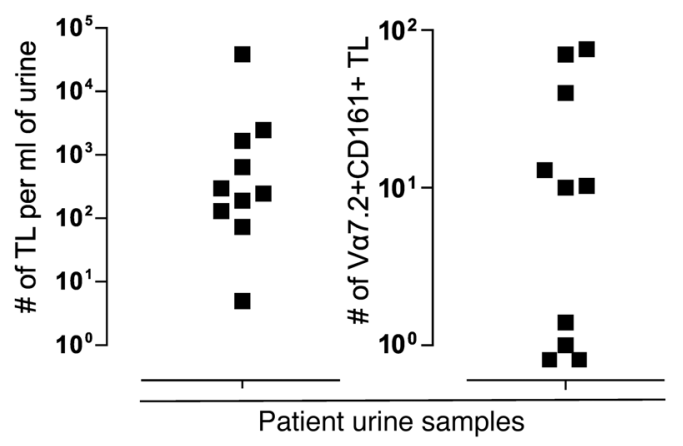

C


$\mathrm{DN} / \mathrm{CD} 8^{\mathrm{lo}}$
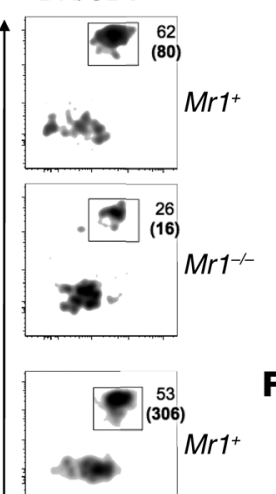

$\mathbf{F}$
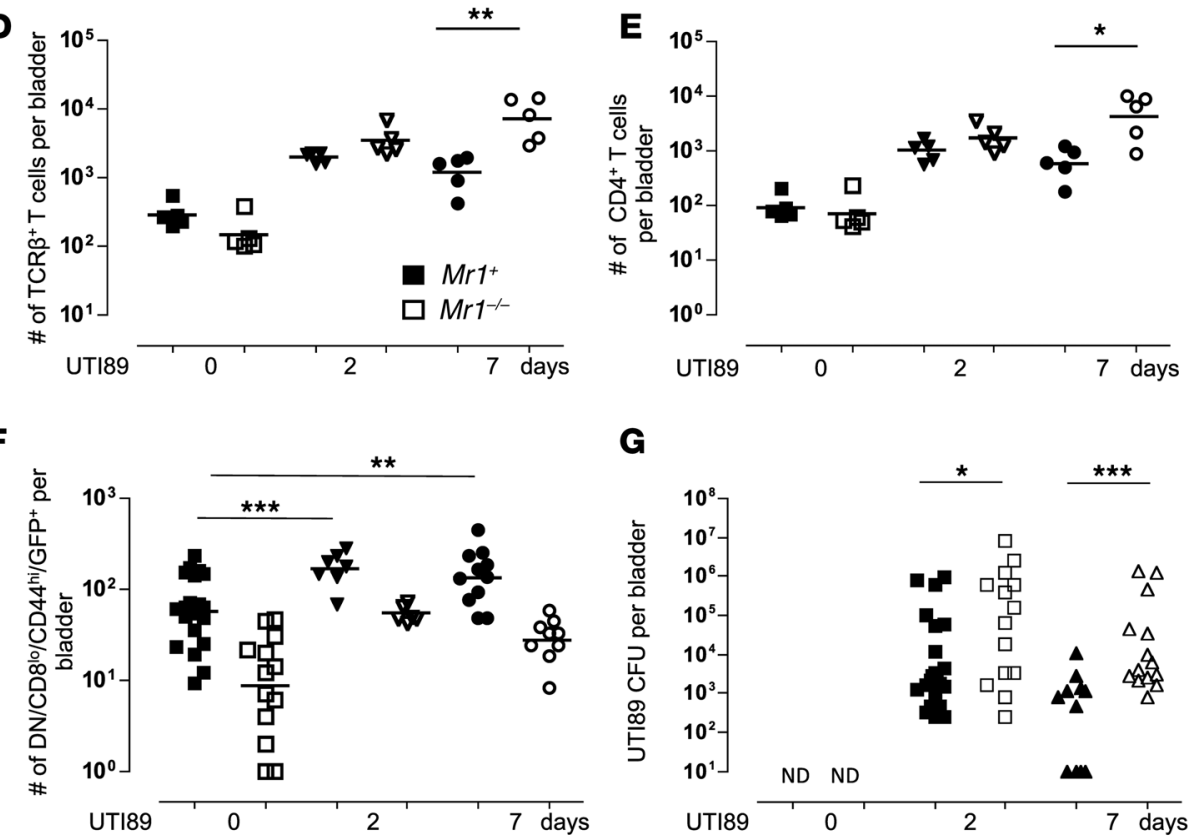

G

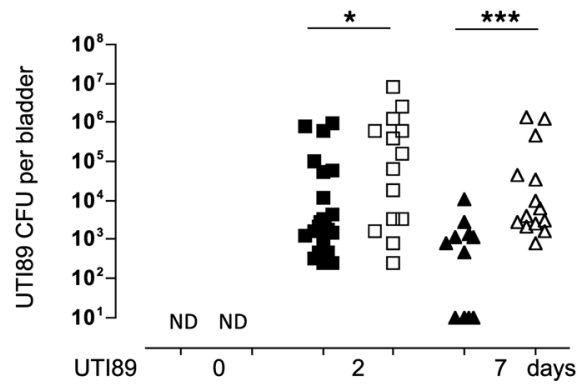

Figure 7. MAITs are recruited to the bladder upon UTI in humans and mice and contribute to bacterial clearance in mice. (A) Gating strategy on TCR- $\gamma \delta^{-} \mathrm{CD}^{+}$T cells isolated from urine samples collected from patients with UTI. (B) Enumeration of MAITs in the urine: number of T lymphocytes (TL) (left panel) and MAITs (right panel) per ml of urine. (C) Flow cytometry analysis of T cells infiltrating bladder from Mr1+ or Mr1 ${ }^{-1-}$ Rorcgt-GFPTC B6-MAIT ${ }^{\text {CAST }}$ mice at day 0 (naive) or 2 or 7 days after infection with UTI89. Representative FACS plots and gating strategy are shown. Numbers in parentheses correspond to total number of cells. (D-F) Quantitation of bladder-infiltrating total T cells (D), CD4+ T cells (E), and MAITs (F) at the indicated time points post infection (p.i.). (G) UTI89 bacterial load in mouse bladders at indicated time points. Pooled data from 2 to 3 independent experiments. ${ }^{*} P<0.05 ;{ }^{* *} P<0.01 ;{ }^{* *} P<0.001$.

cells infiltrating the bladder were analyzed by flow cytometry. We observed robust recruitment of $\alpha \beta$ T cells (Figure 7, C and D), including $\mathrm{CD}^{+}$conventional $\mathrm{T}$ cells (Figure $7 \mathrm{E}$ ) and MAITs (Figure $7 \mathrm{~F}$ ), starting 2 days after infection. Indeed, a significant increase in $\mathrm{GFP}^{+} \mathrm{CD} 44^{\text {hi }} \mathrm{DN} / \mathrm{CD} 8^{\text {lo }} \mathrm{T}$ cell numbers was detected in the infected bladders of $\mathrm{MrI}^{+}$mice at day 2 and was sustained for at least 7 days (Figure 7F). As we observed an overall accumulation of $\mathrm{T}$ cells in the bladder upon infection, we also detected an increase in the absolute number of $\mathrm{GFP}^{+} \mathrm{CD} 44^{\text {hi }} \mathrm{DN} / \mathrm{CD} 8^{\text {lo }} \mathrm{T}$ cells in $M r 1^{\text {neg }}$ mice, but this was always substantially lower than in $\mathrm{Mr}^{+}$littermates. To investigate the antibacterial activity of the infiltrating MAITs, we assessed the bacterial load in infected bladders at different time points. The presence of MAIT in the bladders of $\mathrm{Mr1}^{+}$B6-MAIT ${ }^{\mathrm{CAST}}$ mice was associated with more efficient bacterial clearance than in $\mathrm{MrI}^{-/}$littermates (Figure $7 G)$. Furthermore, a sustained presence of MAITs during the late 
phase of infection (day 7) correlated with lower numbers of conventional $\mathrm{T}$ cells in infected bladders, suggesting more efficient resolution of the inflammation and the potential to enhance the subsequent adaptive immune response, although we did not study this directly. These data indicate that MAITs are present in the bladder and display protective antimicrobial activity.

\section{Discussion}

Although MAIT frequency is modified in several diseases, the role of MAITs in health and disease is still elusive, as no clear evidence associates them with a specific pathology. This can be addressed by studying animal models, but the number of MAITs in SPF-raised conventional laboratory mice is close to the detection limits. Tg mice for the TCR- $\alpha$ or TCR- $\beta$ chains of MAITs are very useful for assessing MAIT reactivity and also to some extent for the study of MAIT selection $(32,36)$. However, the use of TCR Tg mice for functional studies is more challenging because the premature overexpression of the iTCR- $\alpha$ chain leads to artifactual features (41). These caveats are difficult to overcome even with the comparison to an $\mathrm{Mr}^{\text {neg }}$ control, as discussed in the supplementary text of ref. 32. On the other hand, for the available TCR- $\beta$ Tg mice (V $\beta 6$ and V $\beta 8$ ), both chains were isolated from $\mathrm{iV} \alpha 19^{+} \mathrm{T}-\mathrm{T}$ hybridoma recognizing MR1-overexpressing fibroblastic cell lines. Therefore, the potential for autoreactivity of these TCRs against MR1 itself or MR1 loaded with a culture medium component cannot be excluded. Whether this putative autoreactivity affects the selection and functions of the $\mathrm{T}$ cells found in these $\mathrm{Tg}$ mice is currently being studied.

Given the high conservation between species of both the restricting element MR1 and the iTCR- $\alpha$ chain, the disparity between the number of MAITs in humans and laboratory mice is intriguing. Although it was recently shown that MAITs can tremendously expand in B6 mice during bacterial infection by Francisella tularensis and display protective activity after depletion of conventional $\mathrm{T}$ cells (8), it is rather difficult to envision how such a minor subset would drive innate-like response and display protection during natural infection or infections in unmanipulated settings. We set out to understand the reasons for this apparent paradox. Because the reconstitution of germ-free mice with human microbiota did not lead to higher frequency of MAITs than that found in SPF mice, we hypothesized that laboratory mice may have lost an allele or alleles important for the defense against common pathogens due to the absence of selection pressures in the clean animal facilities. Indeed, laboratory mice are not representative of the existing mouse species, as they harbor less than $25 \%$ of the genetic diversity of wild mice (45).

We found 2 wild-derived inbred SPF mouse strains with higher frequency of MAITs. Given the naive phenotype of MAITs we had observed in iTCR- $\alpha \mathrm{Tg}$ mice, we expected that the gene or genes involved in the MAIT ${ }^{\text {hi }}$ phenotype would be implicated in the activation, survival, and/or expansion of MAITs. To our surprise, the 20-fold increase in MAIT frequency found in the CAST strain was linked to 1 locus located at the $3^{\prime}$ end of the TCR- $\alpha$ region, leading to higher production of the specific rearrangement. Although the exact molecular mechanism is not elucidated, the increased number of MAITs was CAST chromosome (Figure 2E) and hematopoietic (Figure 2B) intrinsic and was already observed in the thymus
(Figure 2A). The small difference in MAIT frequency found in the thymus of $\mathrm{MrI}^{+}$versus $\mathrm{Mr1}^{--}$animals (Figure 3A) is consistent with the absence of MAIT accumulation in this organ (32). Indeed, the occurrence of the restricting MHC allele during thymic selection has a small impact on the frequency of naive $\mathrm{T}$ cells specific for many nominal antigens (52).

The lower frequency of iV $\alpha 19^{+}$cells in the periphery of $\mathrm{MrI}^{-1-}$ in comparison with $\mathrm{Mr1}^{+}$animals suggests that MR1 expression in the periphery is necessary for their activation and/or their peripheral expansion and survival. Nevertheless, the peripheral expansion in mice is much lower than in humans, as indicated by the diverse MAIT TCR repertoire in the liver of B6-MAIT ${ }^{\text {CAST }}$ mice, which suggests that MAITs accumulate rather than proliferate in this organ. We also observed that both NKT and EM T cells expanded less in the SPF mice we studied than in humans (Figure 4 and refs. 20,53). This might be a general difference of effector cells between the 2 species and would suggest that the turnover of NKT and MAITs is slower in humans than in mice.

The smaller number of MAITs in SPF B6-MAIT ${ }^{\mathrm{CAST}}$ mice in comparison with humans might be related to differences in the gut microbiota between these 2 species. Although the similar number of MAITs in the LP of SPF mice and germ-free mice colonized by human microbiota (Figure 1A) argues against this hypothesis, it remains to be determined whether MAIT numbers would increase after implantation of human microbiota into B6-MAIT ${ }^{\text {CAST }}$ mice. Although the proportion of type 2 NKT is higher in humans, NKT cells are much more abundant in mice than in humans. Therefore, a competition between MAIT and NKT cells during intrathymic development or for peripheral niches could also be involved. However, NKT cell numbers were not increased in the spleen, MLNs, liver, and LP of $\mathrm{Mr}^{-/-}$mice (data not shown), while MAITs were only slightly increased in $C d 1 d^{-/-}$B6-MAIT ${ }^{\text {CAST }}$ mice (Supplemental Figure 6), arguing against this hypothesis.

In the absence of available MR1 tetramers or anti-Vo19 antibody, we relied on RT-qPCR of the iV $\alpha 19-J \alpha 33$ iTCR- $\alpha$ chain to track MAITs. The iTCR- $\alpha$ chain was only found in the CD $44^{\text {hi }} C D 8^{\text {lo }} \mathrm{DN}$ subset (Figure 3B), confirming that mouse MAITs are not found in the $\mathrm{CD} 4^{+}$or $\mathrm{CD} 8^{\text {hi }}$ subset, as observed in humans. Similarly to what occurs in humans, MAITs were mostly found in tissues such as liver and colon LP (Figure 3A). To facilitate phenotype analysis and allow functional studies, we introgressed an Rorcgt-GFP reporter into the B6-MAIT ${ }^{\text {CAST }}$ congenic strain. Almost all $\mathrm{CD} 44^{\text {hi }} \mathrm{GFP}^{+} \mathrm{CD} 8^{\mathrm{lo}} \mathrm{DN} \mathrm{T}$ cells in adult B6-MAIT ${ }^{\text {CAST }}$ mice expressed the iV $\alpha 19-J \alpha 33$ TCR- $\alpha$ chain (Figure 3D). However, since this subset might also encompass a few CD1d-restricted NKT cells, we verified our lymphokine secretion studies using MAITs from Cd1d ${ }^{-/}$Rorcgt-GFP $^{T G}$ B6-MAIT ${ }^{\text {CAST }}$ mice. Overall, with regard to phenotypic features, mouse MAITs are similar to human ones, assuming that mouse $\mathrm{DN} / \mathrm{CD} 8^{\text {lo }} \mathrm{T}$ cells are orthologous to human DN/CD8 $\alpha \alpha$ and CD8 $\alpha \beta^{\text {lo }} \mathrm{T}$ cells. The presence of IL-18R $\alpha$ and IL-12R $\beta 1$ indicates that mouse MAITs can be activated by innate signals, as are human MAITs (25).

Although MAITs were discovered by identifying an iTCR- $\alpha$ chain in a particular T cell subset (20), in our opinion, MAITs should be defined as T cells educated by MR1 in the thymus to acquire a specific differentiation program. Whether MR1-restricted $\mathrm{T}$ cells are limited to $\mathrm{T}$ cells expressing iV $\alpha 19-\mathrm{J} \alpha 33 \mathrm{iTCR}-\alpha$ (and iV $07.2-\mathrm{J} \alpha 33 / 12 / 20$ in humans, ref. 38) is not yet clear. The data 
above indicate that if other MR1 restricted $\mathrm{T}$ cells with a distinct repertoire exist, they would have to be distinct from the $\mathrm{CD} 44^{\text {hi }} \mathrm{ROR} \gamma \mathrm{t}^{+} \mathrm{CD} 8^{\mathrm{lo}} \mathrm{DN}$ subset. In addition, it remains to be determined whether all MR1-restricted T cells would be labeled with MR1 tetramers loaded with one given ligand. This is true for adult human MAITs (38). In humans, the presence in the cord blood of $\mathrm{T}$ cells expressing high levels of CD161 1 hiL-18R $\alpha^{+}(22)$ that are not $\mathrm{V} \alpha 7.2^{+}$suggests that $\mathrm{T}$ cells with a distinct repertoire can follow a development pathway similar to that of MAITs (54), probably linked to the selection on DP thymocytes (55). Whether all these T cells are MR1 restricted remains to be determined. $(22,56)$

In $\mathrm{Mrl}^{+} \mathrm{iV} \alpha 19 \mathrm{Tg} \mathrm{Ca}^{-/-}$mice, we observed that most $\mathrm{CD}^{+}$ $\mathrm{T}$ cells are neither bacterial reactive nor MR1 restricted $(6,32)$. In contrast, a significant number of MR1-dependent MR1-Tet ${ }^{+}$ $\mathrm{V} \beta 6 / 8.1-2^{+} \mathrm{T}$ cells were $\mathrm{CD} 4^{+}$in another $\mathrm{iV} \alpha 19 \mathrm{Tg}$ line (38). In the current study, in a polyclonal model, in the organs we studied, we did not observe CD4 ${ }^{+}$MR1-restricted T cells, confirming our previous reports $(6,32)$. The origin of these discrepancies between different $\mathrm{iVa19} \mathrm{Tg} \mathrm{Ca}^{-/}$lines might be due to differences in the microbiota of the animal facilities or TCR- $\alpha$ Tg timing or level of expression. Nevertheless, the polyclonal B6-MAIT ${ }^{\mathrm{CAST}}$ mouse model described herein is not subjected to this TCR Tg artifact and largely recapitulates the features of human MAITs.

This new model allowed us to study the phenotype and function of MAITs in mice. Our results are concordant with the MR1-5OP-RU tetramer-based characterization of the rare MAITs found in C57BL/6 mice that has recently been published (48) and confirm the interest of the Rorcgt-GFP ${ }^{T G}$ B6-MAIT ${ }^{\text {CAST }}$ mouse strain. Overall, mouse and human MAITs were very similar with regard to phenotype and lymphokine secretion (21).The few differences we observed were a more diverse repertoire related to a lower peripheral expansion, low CXCR6 expression, and secretion of IL-4 and IL-10. We $(21)$ and others $(25,26,30)$ have never observed such a lymphokine secretion pattern in humans. The impact of MAITs on antibacterial mucosal IgA responses suggested by the slightly lower level of serum IgA will be addressed in further studies. Importantly, like human MAITs, polyclonal mouse MAITs from B6-MAIT ${ }^{\text {CAST }}$ mice expressed both ZBTB16 and ROR $\gamma$ t transcription factors in contrast to our study on $\mathrm{iV} \alpha 19-\mathrm{V} \beta 6$ double-Tg mice (32). The changes in $\mathrm{T}$ cell ontogeny imparted by the premature expression of a TCR- $\alpha$ Tg probably explain these differences.

The origins of the differences between mouse and human MAITs are unclear. With regard to repertoire, all the memory $\mathrm{T}$ cell subsets, whether innate-like or conventional effector, seem to display lower oligoclonality in mice in comparison with humans (Figure 4B and refs. 20,33). Thus, MAITs would be similar to other memory subsets in mice. However, it should be stressed that, in humans, only blood MAITs were studied, whereas the mouse MAITs were isolated from lymphoid organs or tissues.

The availability of a mouse model harboring polyclonal MAITs allowed us to study their putative involvement during an experimental UTI. In line with the human data (Figure 7A), we observed the presence of MAITs in the mouse bladder during UTI. Moreover, MR1-deficient mice exhibited higher bacterial load, in particular at late time points (Figure $7 \mathrm{G}$ ). The larger conventional T cell infiltration in the bladder during infection in the absence of MAITs may be related to higher bacterial load or to a direct effect of MAITs on conventional $\mathrm{T}$ cell accumulation or survival. Therefore, this model will be very useful to study, for instance, the mechanisms of bacillus Calmette-Guérin (BCG) antitumor activity during the treatment of bladder carcinoma (57). This MAIT-rich mouse model will also allow the test of MAIT stimulation with synthetic ligand as a therapeutic tool in various diseases or as an adjuvant for vaccine development.

\section{Methods}

Mice. B6 mice were obtained from Charles Rivers Laboratories. The Mus musculus castaneus (CAST/EiJ) and Mus musculus musculus PWK strains were provided by X. Montagutelli (Institut Pasteur). The Rorcgt-GFP $P^{T G}$ (46) and $C d 1 d^{-/}$lines, both on a B6 background, were provided by G. Eberl (Institut Pasteur) and A. Lehuen (INSERM U1016, Institut Cochin, Paris, France), respectively. The 3 strains were transferred as embryos into our animal facility at Institut Curie. $\mathrm{Tap}^{-/-} \mathrm{Ii}^{-/-} \mathrm{MrI}^{+}$(and $\mathrm{Mr}^{-/-}$) mice have been previously described (32). B6-MAIT ${ }^{\text {CAST }}$ congenic mice were obtained by selecting mice expressing a MAIT ${ }^{\text {hi }}$ phenotype in the blood to be bred to B6 mice for more than 10 generations.

Germ-free $\mathrm{Tap}^{-/-} \mathrm{Ii}^{-/-}$mice were obtained by Cesarean section at the CNRS Central Animal Facility (Orléans, France) and then housed at the ANAXEM Animal Facility, INRA (Jouy-en-Josas, France). The reconstitution with human microbiota was carried out at INRA. Colonization was verified several times during the experiments. At 2 to 3 months after reconstitution, colon LP lymphocytes were collected and MAITs were quantified by real-time RT-qPCR.

Mouse cell preparation. Thymus, spleen, and MLNs were collected into cold PBS with 0.5\% BSA. Lymphocytes were liberated by mechanical disruption over a cell strainer. Livers and lungs were perfused with $10 \mathrm{ml}$ of PBS to remove circulating blood cells. Livers were then dissociated by passing through a $100-\mu \mathrm{m}$ cell strainer and resuspended in PBS with 0.5\% BSA. Lung lobes and chopped skins were digested in $\mathrm{CO}_{2}$-independent media containing 0.5 Wünsch units $/ \mathrm{ml}$ liberase (Roche) and $0.1 \mathrm{mg} / \mathrm{ml}$ DNase I (Roche) at $37^{\circ} \mathrm{C}$ for 30 minutes (lung) to 1 hour (skin) and further dissociated using gentleMACS Dissociator according to the manufacturer's instructions (Miltenyi Biotec). The cell suspensions were filtered through a 100- $\mu \mathrm{m}$ cell strainer. The released cells from liver, lung, and skin were layered on a $40 \% / 80 \%$ Percoll gradient (GE Healthcare) and spun at $800 \mathrm{~g}$ for 20 minutes at room temperature. Mononuclear cells were recovered from the interface. Intestinal lymphocytes were isolated as previously described $(20,57,58)$. Briefly, large intestines were collected in cold PBS. The intestines were carefully flushed and opened longitudinally. Intestinal epithelium was removed by shaking in $60 \mathrm{ml}$ of PBS with $3 \mathrm{mM}$ EDTA for 10 minutes (twice) followed by 15 minutes incubation in $15 \mathrm{ml}$ of $\mathrm{CO}_{2}$-independent medium containing $1.5 \mathrm{mM} \mathrm{MgCl}_{2}$ and $1 \mathrm{mM} \mathrm{EGTA}$ (twice) at $37^{\circ} \mathrm{C}$. The remaining tissue was cut into 1- to $2-\mathrm{mm}$ pieces and digested in $30 \mathrm{ml}$ of $\mathrm{CO}_{2}$-independent medium containing $20 \% \mathrm{FCS}, 100 \mathrm{U} / \mathrm{ml}$ collagenase (type VIII, Sigma-Aldrich), and 5 U/ml DNase I (DN25, Sigma-Aldrich) and shaken for 90 minutes at $37^{\circ} \mathrm{C}$. The tissue suspension was dissociated by syringe aspirations and passed through a cell strainer. Cell suspension was pelleted followed by density gradient centrifuge at $1,000 \mathrm{~g}$ for 25 minutes at room temperature (lympholyte; Cedarlane). LPLs were recovered from the interface.

Cells were cultured in DMEM or RPMI 1640 medium supplemented with $10 \%$ heat-inactivated FCS, $100 \mathrm{U} / \mathrm{ml}$ penicillin, 100 
$\mu \mathrm{g} / \mathrm{ml}$ streptomycin, $2 \mathrm{mM}$ L-glutamine, $10 \mathrm{mM}$ HEPES, and $1 \mathrm{mM}$ sodium pyruvate (Gibco; Thermo Fisher Scientific).

Hematopoietic chimera. Donor BM was flushed from tibia and femur of 2 B6-MAIT ${ }^{\mathrm{CAST}}$ or B6-MAIT ${ }^{\mathrm{B} 6} \mathrm{Mr1}^{+}$Rorcgt-GFP $^{\mathrm{TG}}$ mice. T cells were depleted using autoMACS Pro (Miltenyi) after labeling with antiCD3 microbeads. Two million T cell-depleted BM cells from either donor group were injected into the tail veins of 4 to 5 irradiated CD45.1 recipients $(1.2 \mathrm{Gys})$. Two months after reconstitution, mice were sacrificed and organs were collected for FACS and RT-qPCR analysis.

Mouse Universal Genotyping Array. DNA was extracted from ear punches of 35 MAIT $^{\text {lo }}$ and 31 MAIT $^{\text {hi }}$ mice using the Wizard SV Genomic DNA Purification System according to the manufacturer's instructions (Promega). DNA was then sent to GenSeek (Neogen) for genotyping using the Mouse Universal Genotyping Array (MUGA) chip. Genotyping data were analyzed using an in-house R script. Briefly, MUGA data were filtered for both sample call rate $(\geq 0.90)$ and SNP call frequency $(\geq 0.90)$. A Wilcoxon test was performed to compare heterozygosity at each SNP's location according to MAIT $^{\text {lo }}$ and MAIT ${ }^{\text {hi }}$ groups. Then $P$ values were $\log ^{10}$ transformed and plotted according to chromosomal location.

Mouse TCR- $\alpha$ and TCR- $\beta$ repertoire analysis. TCR- $\alpha$ repertoire study was performed using a $5^{\prime}$ rapid amplification of cDNA end adapted to deep sequencing using an Ion PGM system (Life Technologies, Ion 318 Chip vx; 400 base reads) as described previously (42). TCR- $\beta$ repertoire was analyzed using $\mathrm{V} \beta$-specific primers and $\mathrm{C} \beta$ primers that included CS1 and CS2 sequences at their $5^{\prime}$ end to enable Illumina Sequencing. TCR- $\beta$ repertoires were obtained by sequencing using MiSeq (Illumina, v3 kit; $2 \times 300$ bases paired-end reads, ICGEX platform). Each data set was demultiplexed and trimmed for base quality $(>25)$ and read length ( $>250 \mathrm{bp}$ ). Paired reads were merged using the flash v1.2.10 program (-m30-M135-t10-x0.1) (59). The data have been deposited in the NCBI's Sequence Read Archive (SRA) database (SRR2218429-SRR2218460). Resulting fasta files were then uploaded onto the IMGT/high V-Quest webserver (60) (allele ${ }^{\star} 01$ only), and the Junction file was parsed using an in-house $\mathrm{R}$ script to extract information regarding the V-J combination and the CDR3 nucleotide composition. Only predicted productive TCR rearrangements were kept for downstream analysis. The TCR- $\alpha$ and TCR- $\beta$ repertoire sequencing data were analyzed using $R$ and vegan packages. To normalize for uneven numbers of reads, each data set was subsampled 100 times at a depth of 5,000 reads. Then an average rarefaction matrix was computed from the 100 subsampled tables to draw the rarefaction plots.

Flow cytometry. Flow cytometry was performed with directly conjugated antibodies according to standard techniques and analyzed on FACSAria, Fortessa, and LSRII flow cytometers (BD). DAPI and a 405-nm excitation were used to exclude dead cells. The list of antibodies is available in the Supplemental Methods section.

For transcription factor staining, cells were incubated with the LIVE/ DEAD fixable violet stain (Life Technologies) and Fc block antibody prior to cell-surface marker staining. Cells were then fixed and permeabilized overnight using the BD Cytofix/Cytoperm kit (BD), after which they were incubated with either anti-PLZF or anti-ROR $\gamma$ t antibody

For the detection of cytokines, 8,000 (Figure 5D) or 30,000 (Supplemental Figure 6C) sorted splenocytes were cultured in $50 \mu \mathrm{l}$ RPMI 1640 complete medium in the presence of anti-CD3/CD28 Dynabeads (1:1; Gibco, Thermo Fisher Scientific) for 42 to 45 hours at $37^{\circ} \mathrm{C}$. Cytokines in the supernatant were detected using the Cytometric Bead Array Flex Set (BD Biosciences).
MAIT stimulation with bacteria-derived compound. The preparation of the SPB was previously described (49). Briefly, the bacterial lysate was prepared by growing E. coli, DH5 $\alpha$ ATCC strain, to saturation. The bacteria pellet was resuspended in water at $4^{\circ} \mathrm{C}$ for a week to induce the release of the MAIT ligand. Supernatant was collected, filtered, and phenol-cloroform extracted before being aliquoted and lyophilized for further use. One AU corresponds to $25 \mu \mathrm{l}$ bacterial supernatant. 5-A-RU synthesis and 5-OP-RU preparation have been described elsewhere (49).

Splenocytes from Rorcgt-GFP ${ }^{T G}$ B6-MAIT ${ }^{\mathrm{CAST}}$ mice were depleted of APCs and CD4 ${ }^{+} \mathrm{T}$ cells using anti-CD19, anti-CD11c, antiCD11b, and anti-CD4 MicroBeads (Miltenyi Biotech). Then $3 \times 10^{5}$ MAIT-enriched splenocytes were cultured with $10^{5}$ WT3 or mouse MR1-transfected WT3 (WT3.mMR1) cells (50) that had been preincubated with serial dilutions of semipurified bacterial supernatant or 5-A-RU plus $\mathrm{MeG}$ for 30 minutes at $37^{\circ} \mathrm{C}$. Under some conditions, $10 \mu \mathrm{g} / \mathrm{ml}$ of anti-MR1 blocking Ab (clone 26.5; ref. 61), provided by T. Hansen (Washington University, St. Louis, Missouri, USA), was added before adding the T cells. After overnight culture, activation was analyzed using flow cytometry.

UTI. Urine samples from patients with UTI were obtained from the Microbiology Department of Curie Institute after cytobacteriologic analysis. Samples that tested positive for both bacteria and leukocytes were included in the study.

For the experimental UTI, clinical UPEC, cystitis isolate UTI89, was grown statically for 20 hours in LB broth, washed in PBS, and resuspended for use at 1 to $2 \times 10^{7} \mathrm{CFUs}$ per $50 \mu \mathrm{l}$ (62). Seven- to ten-week-old B6-MAIT ${ }^{\text {CAST }}$ female mice were anesthetized with ketamine $(125 \mathrm{mg} / \mathrm{kg})$ and xylazine $(12.5 \mathrm{mg} / \mathrm{kg})$ intraperitoneally, and a 24-gauge catheter (BD Insyte Autoguard, BD) containing either PBS or UTI89 was inserted through the urethra; $50 \mu \mathrm{l}$ of bacterial suspension or PBS was instilled at a slow rate to avoid vesicoureteral reflux.

At indicated time points, bladders, spleens, and bladder-draining LNs were harvested. Bladder-infiltrating lymphocytes were isolated from tissue digested in $\mathrm{CO}_{2}$-independent medium (Invitrogen) containing Liberase TM $(0.17 \mathrm{U} / \mathrm{ml})$ (Roche), collagenase D $(1 \mathrm{mg} / \mathrm{ml})$ (Roche), and deoxyribonuclease 1 (1 U/ml) (Invitrogen). After 40 minutes incubation at $37^{\circ} \mathrm{C}$ in a shaking incubator, tissue suspensions were pressed through a $40-\mu \mathrm{m}$ cell strainer (Falcon), washed in PBS with $0.5 \%$ BSA and $2 \mathrm{mM}$ EDTA, and pelleted for FACS staining

Quantitative PCR and SNP genotyping. Real-time qPCR was performed as previously described (20). The primers were specific for regions that are identical in B6 and CAST strains. Real-time PCR was performed using a LightCycler 480 (Roche). Fold change in expression was determined by the $2-\Delta \Delta \mathrm{CT}$ method after normalizing to the TCR- $\alpha$ constant region $(C \alpha)$.

SNP genotyping assays were custom designed using TaqMan Assay Design Tool (Life Technologies) on the reference assembly NCBI37/ mm9. SNP queries were performed using the Mouse Genomes Project database (http://www.sanger.ac.uk/sanger/Mouse_SnpViewer/ rel-1505) and the UCSC Genome Browser (http://genome.ucsc.edu/ cgi-bin/hgGateway).

Statistics. All data were analyzed with the 2-tailed nonparametric Mann-Whitney $U$ test using GraphPad Prism v5.0c (GraphPad Software Inc.). Data were considered significant at a $P$ value of less than 0.05. All data are reported as the arithmetic or geometric mean $\pm \mathrm{SD}$ as appropriate. 
Study approval. All animal experiments were performed in an accredited mouse facility in accordance with the guidelines of the French Veterinary Department. The animal protocol was approved by the Animal Ethical Committee of Paris Centre (CEEA-59): file \#2012-0067. Urine from patients with UTIs was obtained at Institut Curie. Following French regulations, all patients were informed that leftovers of specimens obtained for diagnosis or through therapeutic procedures may be used for research purposes.

\section{Author contributions}

YC, KF, YKM, SM, LLB, AK, VP, EM, LD, SR, JPV, and CS performed experiments. $\mathrm{MI}$ and JJ contributed essential reagents or tools. All authors interpreted the data. OL supervised the work, interpreted the data, and wrote the manuscript.

\section{Acknowledgments}

We thank M. Sarkis for synthesizing 5-A-RU; C. Daviaud and I. Grandjean for managing the mouse colony; Z. Maciorowski,
S. Grondin, and A. Viguier for cell sorting; T. Rio Frio of the Next-Generation Sequencing (NGS) platform for advice; D. Laubreton for technical help; A. Lehuen, X. Montagutelli, and G. Eberl for mice; and T. Hansen for the 26.5 antibody and MR1 transfectants. We thank P. Matzinger for her suggestions. We also thank L. Teyton, S. Amigorena, and K. Benlagha for their helpful discussions and review of the manuscript. This work was supported by grants from INSERM, Agence Nationale de la Recherche (ANR), DIM Ile de France, Association pour la Recherche sur la Sclérose En Plaques (ARSEP), Institut Mérieux, and Institut Curie. Y.K. Mburu is a recipient of the Lloyd J. Old Memorial Award and is supported by an Irvington Institute postdoctoral fellowship from the Cancer Research Institute.

Address correspondence to: Olivier Lantz, Laboratoire d'Immunologie and INSERM U932, Institut Curie, 26 rue d'Ulm, 75005 Paris, France. Phone: 33.144324218; E-mail: olivier.lantz@curie.fr.
1. Le Bourhis L, Guerri L, Dusseaux M, Martin E, Soudais C, Lantz O. Mucosal-associated invariant $\mathrm{T}$ cells: unconventional development and function. Trends Immunol. 2011;32(5):212-218.

2. Le Bourhis L, Mburu YK, Lantz O. MAIT cells, surveyors of a new class of antigen: development and functions. Curr Opin Immunol. 2013;25(2):174-180.

3. Treiner E, et al. Selection of evolutionarily conserved mucosal-associated invariant $\mathrm{T}$ cells by MR1. Nature. 2003;422(6928):164-169.

4. Treiner E, Duban L, Moura IC, Hansen T, Gilfillan S, Lantz O. Mucosal-associated invariant T (MAIT) cells: an evolutionarily conserved T cell subset. Microbes Infect. 2005;7(3):552-559.

5. Gold MC, et al. Human mucosal associated invariant T cells detect bacterially infected cells. PLoS Biol. 2010;8(6):e1000407.

6. Le Bourhis L, et al. Antimicrobial activity of mucosal-associated invariant T cells. Nat Immunol. 2010;11(8):701-708.

7. Georgel P, Radosavljevic M, Macquin C, Bahram S. The non-conventional MHC class I MR1 molecule controls infection by Klebsiella pneumoniae in mice. Mol Immunol. 2011;48(5):769-775.

8. Meierovics A, Yankelevich WJ, Cowley SC. MAIT cells are critical for optimal mucosal immune responses during in vivo pulmonary bacterial infection. Proc Natl Acad Sci US A. 2013;110(33):E3119-E3128.

9. Kjer-Nielsen L, et al. MR1 presents microbial vitamin B metabolites to MAIT cells. Nature. 2012;491(7426):717-723.

10. Corbett AJ, et al. T-cell activation by transitory neo-antigens derived from distinct microbial pathways. Nature. 2014;509(7500):361-365.

11. Grimaldi D, et al. Specific MAIT cell behaviour among innate-like $\mathrm{T}$ lymphocytes in critically ill patients with severe infections. Intensive Care Med. 2014;40(2):192-201.

12. Abrahamsson SV, et al. Non-myeloablative autologous haematopoietic stem cell transplantation expands regulatory cells and depletes IL-17 producing mucosal-associated invariant $\mathrm{T}$ cells in multiple sclerosis. Brain. 2013;136(pt 9):28882903.

13. Annibali V, et al. CD161 ${ }^{\text {high }} \mathrm{CD} 8^{+} \mathrm{T}$ cells bear pathogenetic potential in multiple sclerosis. Brain. 2010;134(pt 2):542-554.

14. Magalhaes I, et al. Mucosal-associated invariant T cell alterations in obese and type 2 diabetic patients. J Clin Invest. 2015;125(4):1752-1762.

15. Serriari NE, et al. Innate mucosal-associated invariant T (MAIT) cells are activated in inflammatory bowel diseases. Clin Exp Immunol. 2014;176(2):266-274.

16. Cosgrove C, et al. Early and nonreversible decrease of CD161++/MAIT cells in HIV infection. Blood. 2013;121(6):951-961.

17. Leeansyah E, et al. Activation, exhaustion, and persistent decline of the antimicrobial MR1restricted MAIT-cell population in chronic HIV-1 infection. Blood. 2013;121(7):1124-1135.

18. Wong EB, et al. Low levels of peripheral CD161++CD8+ mucosal associated invariant $\mathrm{T}$ (MAIT) cells are found in HIV and HIV/TB coinfection. PLoS One. 2013;8(12):e83474.

19. Fernandez CS, Kelleher AD, Finlayson R, Godfrey DI, Kent SJ. NKT cell depletion in humans during early HIV infection. Immunol Cell Biol. 2014;92(7):578-590.

20. Tilloy $\mathrm{F}$, et al. An invariant $\mathrm{T}$ cell receptor alpha chain defines a novel TAP-independent major histocompatibility complex class Ib-restricted $\alpha / \beta$ T cell subpopulation in mammals. JExp Med. 1999;189(12):1907-1921.

21. Dusseaux M, et al. Human MAIT cells are xenobiotic resistant, tissue-targeted, CD161hi IL-17 secreting T cells. Blood. 2011;117(4):1250-1259.

22. Walker LJ, et al. Human MAIT and CD $8 \alpha \alpha$ cells develop from a pool of type-17 precommitted CD8 ${ }^{+}$T cells. Blood. 2012;119(2):422-433.

23. Huang S, et al. MR1 antigen presentation to mucosal-associated invariant T cells was highly conserved in evolution. Proc Natl Acad Sci U S A. 2009;106(20):8290-8295.

24. Billerbeck E, et al. Analysis of CD161 expression on human CD8+ T cells defines a distinct func- tional subset with tissue-homing properties. Proc Natl Acad Sci U S A. 2010;107(7):3006-3011.

25. Ussher JE, et al. CD161++ CD8+ T cells, including the MAIT cell subset, are specifically activated by IL-12+IL-18 in a TCR-independent manner. Eur J Immunol. 2014;44(1):195-203.

26. Tang XZ, et al. IL-7 licenses activation of human liver intrasinusoidal mucosal-associated invariant T cells. J Immunol. 2013;190(7):3142-3152.

27. Havenith SH, et al. Analysis of stem-cell-like properties of human CD161++IL-18R $\alpha^{+}$memory $\mathrm{CD}^{+} \mathrm{T}$ cells. Int Immunol. 2012;24(10):625-636.

28. Le Bourhis L, et al. MAIT cells detect and efficiently lyse bacterially-infected epithelial cells. PLoS Pathog. 2013;9(10):e1003681.

29. Kurioka A, et al. MAIT cells are licensed through granzyme exchange to kill bacterially sensitized targets. Mucosal Immunol. 2015;8(2):429-440.

30. Turtle CJ, et al. Innate signals overcome acquired TCR signaling pathway regulation and govern the fate of human CD161(hi) CD8 $\alpha$ semi-invariant T cells. Blood. 2011;118(10):2752-2762.

31. Savage AK, et al. The transcription factor PLZF directs the effector program of the NKT cell lineage. Immunity. 2008;29(3):391-403.

32. Martin E, et al. Stepwise development of MAIT cells in mouse and human. PLoS Biol. 2009;7(3):e54.

33. Lepore M, et al. Parallel T-cell cloning and deep sequencing of human MAIT cells reveal stable oligoclonal TCR $\beta$ repertoire. Nat Commun. 2014;5:3866.

34. Turtle CJ, Swanson HM, Fujii N, Estey EH, Riddell SR. A distinct subset of self-renewing human memory CD8 ${ }^{+} \mathrm{T}$ cells survives cytotoxic chemotherapy. Immunity. 2009;31(5):834-844.

35. Croxford JL, Miyake S, Huang YY, Shimamura M, Yamamura T. Invariant V(alpha)19i T cells regulate autoimmune inflammation. Nat Immunol. 2006;7(9):987-994.

36. Kawachi I, Maldonado J, Strader C, Gilfillan S. MR1-restricted V $\alpha$ 19i mucosal-associated invariant $\mathrm{T}$ cells are innate $\mathrm{T}$ cells in the gut lamina propria that provide a rapid and diverse cytokine 
response. JImmunol. 2006;176(3):1618-1627.

37. Shimamura M, Huang YY, Migishima R, Yokoyama M, Saitoh T, Yamamura T. Localization of NK1.1(+) invariant Va19 TCR(+) cells in the liver with potential to promptly respond to TCR stimulation. Immunol Lett. 2008;121(1):38-44.

38. Reantragoon R, et al. Antigen-loaded MR1 tetramers define $\mathrm{T}$ cell receptor heterogeneity in mucosal-associated invariant T cells. J Exp Med. 2013;210(11):2305-2320.

39. Chua WJ, Truscott SM, Eickhoff CS, Blazevic A, Hoft DF, Hansen TH. Polyclonal mucosaassociated invariant $\mathrm{T}$ cells have unique innate functions in bacterial infection. Infect Immun. 2012;80(9):3256-3267.

40. Sakala IG, et al. Functional heterogeneity and antimycobacterial effects of mouse mucosalassociated invariant $\mathrm{T}$ cells specific for riboflavin metabolites. J Immunol. 2015;195(2):587-601.

41. Terrence K, Pavlovich CP, Matechak EO, Fowlkes BJ. Premature expression of T cell receptor (TCR) $\alpha \beta$ suppresses TCR $\gamma \Delta$ gene rearrangement but permits development of $\gamma \Delta$ lineage T cells. J Exp Med. 2000;192(4):537-548.

42. Vera G, et al. Cernunnos deficiency reduces thymocyte life span and alters the T cell repertoire in mice and humans. Mol Cell Biol. 2013;33(4):701-711.

43. Bosc N, Lefranc MP. The mouse (Mus musculus) $\mathrm{T}$ cell receptor $\alpha$ (TRA) and $\Delta$ (TRD) variable genes. Dev Comp Immunol. 2003; $27(6-7): 465-497$.

44. Guo J, et al. Regulation of the TCR $\alpha$ repertoire by the survival window of CD4(+)CD8(+) thymocytes. Nat Immunol. 2002;3(5):469-476.

45. Keane TM, et al. Mouse genomic variation and its effect on phenotypes and gene regulation. Nature. 2011;477(7364):289-294.

46. Lochner $\mathrm{M}$, et al. In vivo equilibrium of proinflammatory $\mathrm{IL}^{-} 17^{+}$and regulatory $\mathrm{IL}-10^{+} \mathrm{Foxp}^{+}$ ROR $\gamma \mathrm{t}^{+}$T cells. JExp Med. 2008;205(6):1381-1393.

47. Bautista JL, et al. Intraclonal competition limits the fate determination of regulatory $\mathrm{T}$ cells in the thymus. Nat Immunol. 2009;10(6):610-617.

48. Rahimpour A, et al. Identification of phenotypically and functionally heterogeneous mouse mucosal-associated invariant T cells using MR1 tetramers. JExp Med. 2015;212(7):1095-1108.

49. Soudais C, et al. In vitro and in vivo analysis of the gram-negative bacteria-derived riboflavin precursor derivatives activating mouse MAIT cells. J Immunol. 2015;194(10):4641-4649.

50. Huang S, et al. MR1 uses an endocytic pathway to activate mucosal-associated invariant $\mathrm{T}$ cells. JExp Med. 2008;205(5):1201-1211.

51. Mulvey MA, Schilling JD, Hultgren SJ. Establishment of a persistent Escherichia coli reservoir during the acute phase of a bladder infection. Infect Immun. 2001;69(7):4572-4579.

52. Legoux F, Debeaupuis E, Echasserieau K, De La Salle H, Saulquin X, Bonneville M. Impact of TCR reactivity and HLA phenotype on naive CD8T cell frequency in humans. J Immunol. 2010;184(12):6731-6738.

53. Dellabona P, Padovan E, Casorati G, Brockhaus M, Lanzavecchia A. An invariant V $\alpha 24-J \alpha$ Q/
V $\beta 11 \mathrm{~T}$ cell receptor is expressed in all individuals by clonally expanded CD4-8- T cells. J Exp Med. 1994;180(3):1171-1176.

54. Fergusson JR, et al. CD161 defines a transcriptional and functional phenotype across distinct human T cell lineages. Cell Rep. 2014;9(3):1075-1088.

55 . Seach N, et al. Double-positive thymocytes select mucosal-associated invariant T cells. J Immunol. 2013;191(12):6002-6009.

56. Leeansyah E, Loh L, Nixon DF, Sandberg JK. Acquisition of innate-like microbial reactivity in mucosal tissues during human fetal MAIT-cell development. Nat Commun. 2014;5:3143.

57. Biot C, et al. Preexisting BCG-specific T cells improve intravesical immunotherapy for bladder cancer. Sci Transl Med. 2012;4(137):137ra72.

58. Arstila T, et al. Identical T cell clones are located within the mouse gut epithelium and lamina propia and circulate in the thoracic duct lymph. JExp Med. 2000;191(5):823-834.

59. Magoc T, Salzberg SL. FLASH: fast length adjustment of short reads to improve genome assemblies. Bioinformatics. 2011;27(21):2957-2963.

60. Li S, et al. IMGT/HighV QUEST paradigm for T cell receptor IMGT clonotype diversity and next generation repertoire immunoprofiling. Nat Commun. 2013;4:2333.

61. Huang S, et al. Evidence for MR1 antigen presentation to mucosal-associated invariant T cells. J Biol Chem. 2005;280(22):21183-21193.

62. Hung CS, Dodson KW, Hultgren SJ. A murine model of urinary tract infection. Nat Protoc. 2009;4(8):1230-1243. 